Alma Mater Studiorum - Università di Bologna DEPARTMENT OF ECONOMICS

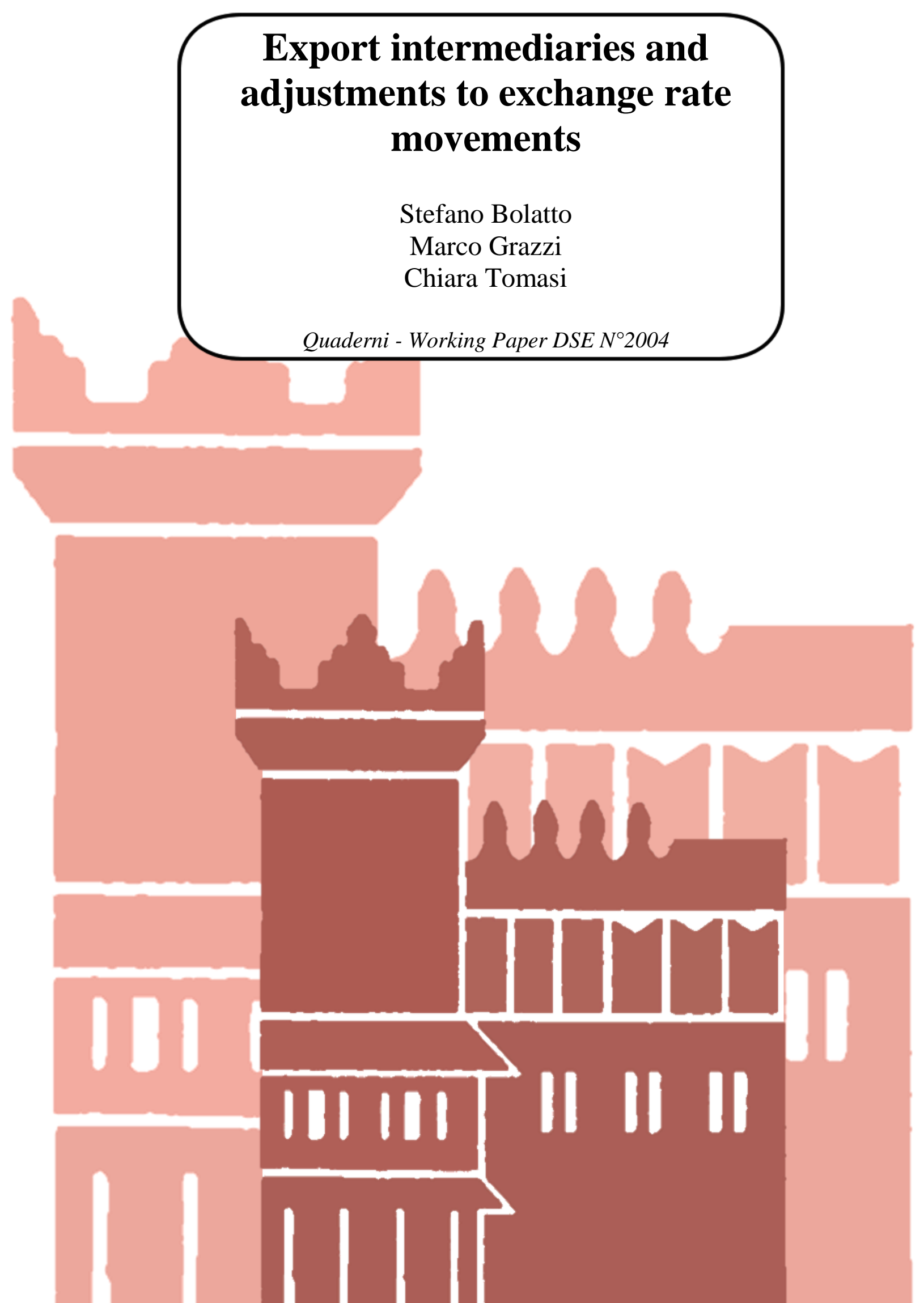




\title{
EXPORT INTERMEDIARIES AND ADJUSTMENTS TO EXCHANGE RATE MOVEMENTS*
}

\author{
Stefano Bolatto ${ }^{\dagger}$ \\ Department of Economics, University of Bologna \\ Marco Grazzi \\ Department of Economics, University of Bologna \\ Chiara Tomasi ${ }^{\S}$ \\ Università degli Studi di Trento 8 LEM Scuola Superiore S.Anna
}

\begin{abstract}
Building on a heterogeneous-firm model à la Melitz (2003), we propose a theory of intermediaries in international trade which rationalizes the available evidence on both aggregate and firm-level exports as well as their responsiveness to exchange rate movements. We introduce double marginalization for goods traded indirectly, i.e. through intermediaries, and local distribution costs for all exporting firms, either intermediaries or direct exporters. This leads to heterogeneous markups, pricing-to-market and to a lower degree of exchange rate pass-through for goods exported by intermediaries. This result, validated on Italian firm-level trade data, is consistent with productivity sorting in the export mode and with the propensity of high productivity firms to absorb more exchange rate movements in their markups. We also explore how direct and intermediary export flows to a given destination react to exchange rate movements along the extensive margin of adjustment. Consistently with our theory, we find evidence of a larger variation in the overall number of varieties traded along the intermediary channel.
\end{abstract}

JEL codes: F12, F14, D22. L22.

Keywords: international trade, firms heterogeneity, intermediaries, export entry costs, local distribution costs, heterogeneous markups, product adding and dropping, exchange rate passthrough.

${ }^{*}$ This paper builds upon the preliminary evidence of a project on intermediaries in international trade (NBER Working Paper No. 17711). We want to thank Andrew Bernard, who was also involved in that project, for insightful suggestions. The present work has been possible thanks to a research agreement between the Italian Statistical Office (ISTAT) and the Scuola Superiore Sant'Anna. We gratefully acknowledge for insightful discussions Federico Boffa, Luca Lambertini and Gianmarco Ottaviano. All errors remain our own.

${ }^{\dagger}$ Strada Maggiore 45, 40125 Bologna, Italy, tel: +39 051 2092651, email: stefano.bolatto@unibo.it

${ }^{\ddagger}$ Piazza Scaravilli 2, 40126 Bologna, Italy. tel: +39 051 2098130, email: marco.grazzi@unibo.it

$\S$ Via Inama 5, 38122 Trento, Italy, tel: +39 0461 282161, email: chiara.tomasi@unitn.it 


\section{Introduction}

A well established body of research has shown that, together with manufacturing firms that directly manage the exchange with their foreign customers, there are firms that do not engage in production activities but simply serve as intermediaries, assisting manufacturing producers in reaching overseas markets. The role of wholesalers in international trade has been largely investigated both from a theoretical and empirical perspective ${ }^{1}$

In particular, the empirical research has highlighted some key-features of intermediation in trade. First, intermediaries account for a relevant share of activities in international trade $2^{2}$ Second, exports through an intermediary increase the number of manufacturing firms that can reach foreign markets with their goods. Moreover, for an indirect exporter intermediated trade can be a transition to become direct exporter $3^{3}$ Third, manufacturing firms tend to endogenously select their mode of exports -either direct or indirect, i.e. through an intermediary- based on their own productivity. Fourth, intermediaries are relatively more important in markets that are more difficult to penetrate, whereas their incidence declines with both market size and the degree of product differentiation. Fifth, such different characteristics of direct exporters and intermediaries bear relevant consequences on aggregate trade flows; more in detail, aggregate exports to destinations with high shares of intermediary exports are less responsive to changes in the real exchange rates than exports to markets served primarily by direct exporters 4

This paper contributes to the existing literature on the role of intermediaries in international trade by bringing new evidence on the reaction of these firms to exchange rate movements, both at the micro-level (in terms of firms' price and exports elasticity) and at the macro-level (in terms of extensive margins). We propose a theoretical framework that, beyond accommodating and rationalizing most of the stylized facts on trade intermediaries, also enables to frame our new empirical findings.

In particular, we outline a relatively parsimonious model of trade featuring heterogeneous markups and pricing-to-market. A key-feature of our model is that markups also differ by the type of firm (intermediary, indirect manufacturer exporter or direct manufacturer exporter) and this, in turn, leads to a differential response of these types of firms to common external shocks,

\footnotetext{
${ }^{1}$ Among the studies that theoretically address the presence of intermediary firms in international trade, see Rauch and Watson (2004); Raff and Schmitt (2006); Raff and Schmitt (2009); Antràs and Costinot (2011); and Bai et al. (2016). Empirical analyses can instead be found in Bernard et al. (2010); Ahn et al. (2011); Bernard et al. (2015); Crozet et al. (2013); Grazzi and Tomasi (2016); and Davies and Jeppesen (2015), among others. Finally, it is worth mentioning an emerging line of research delving into the phenomenon of the so-called Carry-along Trade (CAT), i.e. the increasing propensity of manufacturing firms to also operate as trade intermediaries, thereby exporting goods that they do not produce. For more details on this topic, we refer to Bernard et al. (2012) and DiNino (2015).

2 Bernard et al. (2010) report that $35 \%$ of US exporters are wholesalers, accounting for $10 \%$ of exports by value. Figures are similar for Italy (Bernard et al. 2015), whereas the shares of intermediaries' exports are larger (respectively, 15\% and 20\%) in Sweden (Akerman, forthcoming) and France (Crozet et al., 2013). In China around one quarter of the total export value takes place through wholesalers (Ahn et al. |2011).

${ }^{3}$ Using survey data, Grazzi and Tomasi (2016) show that the possibility to export indirectly increases by more than a quarter the number of firms that can reach foreign markets with their goods. Using data from Ghana, Ahn et al. 2011) observes that firms using intermediaries have a substantially higher probability of subsequently exporting directly.

${ }^{4}$ This evidence, in particular, is documented in Bernard et al. (2015).
} 
such as (real) exchange rate movements. At the core of the model there are two set of predictions. First, our theory predicts that exchange rate pass-through not only is incomplete but, most interestingly, is lower for products that are sold by intermediaries rather than by direct exporters. Indeed, the exchange rate elasticity of export prices is higher for intermediaries than for direct exporters. Moreover, as a result of the lower degree of exchange rate pass-through that characterizes the wholesalers, exports of intermediaries (in value) are less elastic to exchange rate movements as compared to those of direct exporters. Second, in term of extensive margin, the model predicts that the overall number of varieties exported by intermediaries is more sensitive to exchange rate movements if compared to the number of varieties traded directly. This is because a change in the domestic currency changes the minimum level of productivity which is required for making export a profitable activity. However, if the density of firm level productivities is monotonically (weakly) decreasing, then the range of varieties dropped by intermediaries in response to a real appreciation exceeds that of direct exporters.

Our theory builds on a standard Melitz's (2003) type of economy with monopolistic competition. As in Corsetti and Dedola (2005), we assume that exporting does not simply entail paying a fixed cost of entry in the foreign market and incurring a standard iceberg trade cost, but also entails paying distribution costs in the overseas market, these costs being expressed in the foreign currency. Hence, the price paid by foreign consumers is the sum of two components: the export price set by the producer, expressed in the foreign currency and already inclusive of iceberg costs, and a local per-unit distribution cost. In the spirit of Akerman (forthcoming), our model also features double marginalization: intermediaries charge their own markup over the price that they pay for procuring the variety to be sold abroad, this price, in turns, being already inclusive of the producer's markup.

Assuming distribution costs abroad generates pricing-to-market by all type of firms and therefore heterogeneous markups across destination markets, which is key to justify incomplete exchange rate pass-through 5 However, local distribution costs alone are not enough to motivate the different degree of exchange rate pass-through that characterizes the direct and intermediary export channels. An obvious explanation in this respect is that the higher price adjustment is related to the price setting mechanism in the intermediary channel, that we model as a double marginalization ${ }^{6}$ At odds with manufacturing exporters, intermediaries may spread the fixed cost of export across more than one good, but covering this cost requires them to charge a markup between the procurement price of the goods and what they charge to their foreign customers.7 In our theoretical setting

\footnotetext{
${ }^{5}$ Unless assuming demand function à la Melitz and Ottaviano, 2008, a simple model of export intermediation with no local distribution costs would easily entails productivity sorting in the selection of the mode of export, but would also imply that the exchange rate pass-through is necessarily complete, as far as markups would be neither firm-and-market-specific.

${ }^{6} \mathrm{~A}$ well-established literature in industrial organization, starting from Spengler $(1950)$, shows that efficiency typically requires the adoption of a two-part tariff, thereby avoiding double marginalization along the vertical channel. However, there are reasons (discussed at length in Section 3.1) to believe that a two-part tariff, at least in its most common version, is not suitable for the case of export intermediation. Furthermore, the propensity of intermediaries to change more their product mix even unconditionally from exchange rate movements (Bernard et al., 2011) plays against the arrangement of stable relationships between intermediaries and indirect exporters, which in turn complicates the adoption of non-linear pricing schemes.

${ }^{7}$ In the eyes of a manufacturing firm, this additional markup represents the main cost of exporting through a trade intermediary and thus plays the same role as the per-unit cost to prepare the variety for the foreign market
} 
double marginalization is also what causes productivity sorting in the choice of the export mode. The most productive firms would indeed prefer to incur their own fixed cost of exporting thus avoiding the further increase in price when the transaction is handled by a wholesaler. On the contrary, other producers would accept incurring in double marginalization, as long as their own productivity is not sufficient to gain positive profits once the fixed cost of entry in the foreign market is accounted for.

We test the theoretical predictions of our model using a dataset that collects all cross-border transactions of Italian firms from 2000 to 2007. The same set of data was also employed in Bernard et al. (2015) which however addressed aggregate trade flows of intermediaries and direct exporters. Here instead we focus on the reaction of intermediaries to exchange rate movements in terms of their price and exports and in terms of extensive margin. Consistently with the model our analysis confirms that intermediaries adjust more their export prices to exchange rate movements and therefore they have lower exchange rate pass-through. As a consequence, we observe that the elasticity of wholesalers' export sales to exchange rate change is lower than that of direct exporters. As far as the extensive margin is concerned, our evidence suggests that the scope of intermediaries - i.e. the range of varieties that intermediaries sell in a given foreign market changes in the aftermath of exchange rate movements. Precisely, the number of varieties dropped by intermediaries as a consequence of the appreciation of the real exchange rate is higher than that of direct exporters.

Our paper relates to two strands within the international trade literature. First, our paper is mostly related to the growing literature on intermediated trade. Our paper differentiates from the existing studies in several ways. We allow for heterogeneous markups, pricing-to-market and incomplete pass-through by introducing a local per-unit distribution cost, as done by Chatterjee et al. (2013) and Bernini and Tomasi (2015). In this manner, instead of having the Dixit-Stiglitz markup imposed twice for goods exported through intermediaries, we obtain a more sophisticated configuration in which the markup varies with the firm type. This enables to account for the observed differences in pricing behavior of the various exporting firms, as well as their different response to common external shocks. Another relevant difference with respect to the previous contributions is that we abstract away from assuming an optimal size for intermediaries $8^{8}$

Secondly, this paper is also related to a very recent literature on exporters' heterogeneity and pricing-to-market behavior. The seminal article by Berman et al. (2012) shows that more productive exporters are more capable to reduce the ERPT into the consumer import prices. Amiti et al.

introduced by Ahn et al. (2011). Both these elements indeed generate a trade-off in exporting indirectly: while the manufacturer gets rid of the fixed cost of entry in the foreign market, its sales abroad declines because of the higher price implied by either the additional markup of the intermediary or the ad-hoc per-unit cost.

${ }^{8}$ In Akerman (forthcoming), the existence of non-exporting firms in the presence of trade intermediaries is justified by the cost of the intermediary's distribution network being convex and increasing in product scope (i.e. in the range of exported goods): a more complex product portfolio is indeed more costly to handle. This limits the economies of scope and leads to an optimal scope for wholesalers. Given the number of intermediary firms that are available, the least productive manufacturers might not be able to find wholesalers that are willing to export their products. In our model, the existence of non-exporting firms is instead granted by assuming a fixed cost that manufacturing firms have to pay in order to access the intermediary sector; this fixed cost is obviously lower than what required for direct exporting. 
(2014) observe that import-intensive exporters have significantly lower exchange rate pass-through. Chatterjee et al. (2013) study the effect of exchange rate shocks on the export behavior of multiproduct firms, while Bernini and Tomasi (2015) investigate the heterogeneous response of exporters to real exchange rate fluctuations due to the quality of imported inputs and exported output. Our paper contributes to this literature on the heterogeneous pricing to market strategies of exporters by bringing empirical evidence on the difference between intermediaries and direct exporters in their response to real appreciations (and depreciations).

Interestingly, our findings do not conflict with the key conclusion of Berman et al. (2012), according to which in the aftermath of an exchange rate appreciation, more productive firms decrease producer prices further than less productive firms. Due to productivity sorting in the export mode selection, intermediaries trade goods produced by firms with lower levels of productivity than manufacturing direct exporters; however, the price adjustment is larger in case of goods exported through intermediaries as a result of a double adjustment. The indirect manufacturer exporter adjusts the producer price, although to a lesser extent than a direct exporter. Then, also the intermediary adjusts its own markup over the procurement price that it pays to the indirect exporter. As a result, the overall price adjustment is larger for goods subject to double marginalization, that is those exported via intermediaries.

The paper is organized as follows. Section 2 introduces the model by considering the basic setup without intermediaries and illustrates the main results for the case of direct export, particularly in terms of pricing. In Section 3 we introduce the presence of intermediaries in international trade and we derive the export price elasticities to exchange rate movements for the two categories of exporters, as well as the extensive margin of adjustment in the number of varieties traded along the two export channels. In Section 4 we describe the data and test the predictions put forth in the theoretical part. Section 5 concludes.

\section{The model: basic set-up without intermediaries}

\subsection{Preferences, Production, Trade}

We consider an economy in which preferences are Cobb-Douglas in the quantities consumed of a homogeneous good $O$ and a non-homogeneous good $M$, available in many differentiated varieties. We index each of these varieties by $i$ and we assume that their elasticity of substitution is $\sigma>2$. Under these assumptions, the demand for variety $i$ is simply $q_{i}=A p_{i}^{-\sigma}$, where $p_{i}$ is the price of the variety and $A \equiv \alpha w L P^{1-\sigma}$ is a demand shifter which depends on the wage rate $w$ (our numeraire), the labor force $L$ and the CES price-index of the non-homogeneous good, namely $P$. It also depends on $\alpha \in[0,1]$, which is the share of spending in the $M$ sector.

We assume that the homogeneous good $O$ is produced under perfect competition and using a linear technology which requires only labor as an input. The unit price of this good is then $p_{O}=w=1$, whereas the quantity produced is $x_{O}=L_{O}$, where $L_{O}$ is the amount of labor employed in this production. In the non-homogeneous good sector, namely $M$, each firm $i$ produces instead a unique differentiated variety, according to the following production function: $q_{i}=\varphi_{i} L_{i}$, where 
$L_{i}$ is the amount of labor employed by firm $i$. With $\varphi_{i}$ we denote instead the level of marginal productivity of firm $i$, which is drawn from a generic distribution $G(\varphi)$.

Because of monopolistic competition in sector $M$, firms charge a constant mark-up over their marginal cost. The profit-maximizing price in case of domestic sales is the solution to the following problem: $\max _{p_{i}} \pi_{i}=p_{i} \cdot q_{i}\left(p_{i}\right)-\frac{1}{\varphi} \cdot q_{i}\left(p_{i}\right)-f_{D}$; thus it corresponds to

$$
p_{i}=\underbrace{\frac{\sigma}{\sigma-1}}_{\equiv \mu_{i}} \cdot \frac{1}{\varphi_{i}} .
$$

Regardless of their heterogeneity in productivity levels, when selling at home all firms thus impose the same (Dixit-Stiglitz) markup, namely $\mu_{i}=\mu \equiv \sigma /(\sigma-1)$ for any $i \in(0, N)$.

When opening the economy to the rest of the world, we consider the existence of local distribution costs in the foreign market, as put forth in Corsetti and Dedola (2005) and Chatterjee et al. (2013). Let international trade be costless in the homogeneous-good sector and costly in the differentiated-good sector. Firm $i$ will charge a price $p_{i}^{*}$ for the product to be exported, when expressed in the domestic currency. However, due to the presence of transport and distribution costs, the price in the foreign currency actually paid by foreign consumers will be

$$
\widetilde{p}_{i}^{*}=\tau \varepsilon p_{i}^{*}+\eta^{*} w^{*}
$$

where $\tau$ is a standard iceberg cost, $\varepsilon$ is the exchange rate between the two currencies, and $\eta^{*} w^{*}$ is the level of distribution costs to be paid in the foreign currency (for this reason they are expressed in terms of the wage rate abroad, denoted as $\left.w^{*}\right)$.

Consider now a generic exporting firm $i$. The profit-maximizing price for its foreign sales, denoted as $p_{i}^{*}$, solves the problem: $\max _{p_{i}^{*}} \pi_{i}^{*}=p_{i}^{*} \cdot q_{i}^{*}\left(\widetilde{p}_{i}^{*}\right) \cdot \tau-\frac{1}{\varphi} \cdot q_{i}^{*}\left(\widetilde{p}_{i}^{*}\right) \cdot \tau$, and turns out to be

$$
p_{i}^{*}=\underbrace{\frac{\sigma}{\sigma-1}\left(1+\frac{\eta^{*} \varphi_{i}}{\sigma \tau \epsilon}\right)}_{\equiv \mu_{i}^{*}} \cdot \frac{1}{\varphi_{i}},
$$

where $\epsilon \equiv \varepsilon w / w^{*}$ (with $w=1$ ) is the real exchange rate (RER) between the home and the foreign country. As far as markets are segmented due to the presence of local distribution costs, exporting firms engage in price discrimination between foreign and domestic consumers. Given $\eta^{*} \varphi_{i}>0$ and $\sigma \tau \epsilon>0$, the export-sales markup, denoted as $\mu_{i}^{*}$, is indeed larger than $\mu_{i}$, the Dixit-Stiglitz markup applied on domestic sales. Moreover, $\mu_{i}^{*}$ also differs across firms, as opposed to $\mu_{i}$. According to equation (2), the export-sales markup is: (i) increasing in a firm's productivity $\varphi_{i}$ and in the level of local distribution costs $\eta^{*}$; and (ii) decreasing in the real exchange rate $\epsilon$, in the level of iceberg trade $\operatorname{costs} \tau$ and in the elasticity of substitution $\sigma$.

Notice that, as long as the intermediary sector in not accounted for, our model replicates the framework in Chatterjee et al. (2013) and the export price set by national producers is therefore the same as in their setting. In our model, however, equation (2) only applies to direct export sales; in Section 3, we will show what happens when trade intermediaries are introduced. 


\subsection{Productivity cut-offs}

Firms operating in the non-homogeneous good sector will self-select into the foreign market based on the well-known mechanisms described by Melitz (2003). The firm's marginal productivity is drawn from a probability distribution $G(\varphi)$, after having sunk $f_{E}$ units of labor to develop a new variety. Having learned its own $\varphi_{i}$, each firm will decide on entry in the domestic market (by paying a fixed cost $f_{D}$ ) as well as on entry in the foreign market (by paying a fixed cost $f_{X}$ ). Firms simply face a constant Poisson hazard rate of forced exit, denoted as $\delta$.

As documented in Appendix A1, the critical level of productivity for entry in the domestic market is

$$
\varphi_{D}=\frac{1}{\left(\frac{\psi A}{f_{D}}\right)^{\frac{1}{\sigma-1}}}, \text { where } \psi \equiv \frac{(\sigma-1)^{\sigma-1}}{\sigma^{\sigma} \delta}
$$

whereas the cut-off level for entry in the foreign market is

$$
\varphi_{X}^{\prime}=\frac{\tau \varepsilon}{\left(\frac{\psi A^{*}}{\varepsilon f_{X}}\right)^{\frac{1}{\sigma-1}}-w^{*} \eta^{*}} .
$$

As in Akerman (forthcoming), we use the notation $\varphi_{X}^{\prime}$ to distinguish the export cut-off in the model without intermediaries from the direct export cut-off, introduced in Section 3.3 , that emerges in the presence of an intermediary sector.

When trade intermediaries are not contemplated, only firms with a marginal productivity larger than $\varphi_{X}^{\prime}$ will choose to export; firms with productivity between $\varphi_{D}$ and $\varphi_{X}^{\prime}$ will serve the domestic market only and firms with productivity lower than $\varphi_{D}$ will exit immediately. This sorting pattern corresponds to a well-known result in trade literature, which holds even in a setting augmented with local distribution costs, although conditional on imposing

$$
f_{X}>f_{D}\left[\tau \varepsilon^{\frac{\sigma}{\sigma-1}}+w^{*} \eta^{*}\left(\frac{\psi A^{*}}{\varepsilon f_{D}}\right)^{-\frac{1}{\sigma-1}}\right]^{1-\sigma}
$$

The above condition generalizes the restriction $f_{X}>f_{D} \tau^{1-\sigma}$ to be imposed in the corresponding model without wholesalers 9

\section{The model with export intermediaries}

\subsection{Pricing to market}

We now introduce an intermediary sector, in which firms assisting the non-homogeneous good producers in reaching overseas markets have free access. We assume that intermediaries do not engage in any production activity and do not operate in the domestic market, in which manufacturing firms may distribute their products at zero cost.

\footnotetext{
${ }^{9}$ It can easily be proved that equation (3) generalizes the restriction $f_{X}>f_{D} \tau^{1-\sigma}$ : it suffices to consider the case in which local distribution costs are zero, with the RER that plays no role in the exporting firms' decision on pricing (the RER is one).
} 
To gain access to the services of trade intermediation, any producer aimed at reaching the foreign market has to pay a sunk cost $f_{X^{i n d}}=\lambda f_{X^{d i r}}$ where $f_{X^{d i r}}=f_{X}$. Hence, $\lambda \in(0,1)$ is the relative size of the fixed costs associated with the two modes of export that are now available, i.e. the direct mode in which the manufacturing firm itself handles the transaction of the goods abroad and the indirect one, in which the producer requires the assistance of an intermediary firm.

Once an intermediary has been contracted by a manufacturer, the former gets the exclusive right to sell abroad the good produced by the latter (indirect exporter). With this assumption, we rule out the possibility that a given product $i$ might be exported to a given destination by more than one intermediary. Moreover, as in Akerman (forthcoming), we assume that indirect exporters are randomly matched with intermediary firms; this implies that in equilibrium all intermediaries will "inherit", on average, the same productivity of the representative indirect exporter.

Any intermediary faces the same CES demand faced by manufacturers that export directly. The intermediary firm $j$ pays a price $p_{i j}$ for procuring the good manufactured by producer $i$ and therefore sells the good in the foreign market at the following price (expressed in the foreign currency):

$$
\widetilde{p}_{i j}^{*}=\varepsilon \tau p_{i j}^{*}+w^{*} \eta^{*}
$$

where $p_{i j}^{*}$ is the FOB export price in the domestic currency, set by intermediary $j$ before shipping abroad. This price is the one that maximizes the intermediary's profit from sales of good $i$ in the foreign market conditional to the procurement price $p_{i j}$ paid to the indirect exporter, i.e. the manufacturer of good $i$.

By solving the problem $\max _{p_{i j}^{*}} \pi_{i j}^{*}=p_{i j}^{*} \cdot q_{i j}\left(\widetilde{p}_{i j}^{*}\right) \cdot \tau-p_{i j} \cdot q_{i j}\left(\widetilde{p}_{i j}^{*}\right) \cdot \tau$, we get

$$
p_{i j}^{*}=\underbrace{\frac{\sigma}{\sigma-1}\left(1+\frac{\eta^{*}}{\sigma \tau \epsilon p_{i j}}\right)}_{\equiv \mu_{j}^{*}} \cdot p_{i j},
$$

where $\epsilon$ is, again, the RER between the two countries.

The optimal export price for intermediary $j$ thus depends on the procurement price $p_{i j}$, the latter being, in turn, the price that maximizes the profit of the indirect exporter $i$, i.e. the solution to the problem $\max _{p_{i j}} \pi_{i j}=p_{i j} \cdot q_{i j}\left(\widetilde{p}_{i j}^{*}\right) \cdot \tau-\frac{1}{\varphi_{i}} \cdot q_{i j}\left(\widetilde{p}_{i j}^{*}\right) \cdot \tau$. It is straightforward to show that

$$
p_{i j}=\underbrace{\frac{\sigma-1}{\sigma-2}\left(1+\frac{\eta^{*} \varphi_{i}}{(\sigma-1) \epsilon \tau}\right)}_{\equiv \mu_{i j}} \cdot \frac{1}{\varphi_{i}} .
$$

For goods exported through intermediaries, the price paid by foreign consumers is the result of a double marginalization. Indeed, the intermediary firm $j$ charges its own markup, denoted as $\mu_{j}^{*}$, over the procurement price paid to the manufacturer of good $i$. This price, in turn, already includes the markup $\mu_{i j}$ that firm $i$ imposes over its marginal cost of production when selling to intermediaries. It is worth noticing that the markup $\mu_{i j}$ is larger than the Dixit-Stiglitz markup $\mu_{i}$ that the same manufacturing firm would impose in case of domestic sales to national consumers. When contracting a given intermediary $j$, producer $i$ sells its product to $j$ together with the exclusive right to supply 
that good to the foreign consumers. This enables $i$ to discriminate between domestic consumers and intermediaries. By internalizing the future sales of the intermediary, firm $i$ will therefore charge $j$ with a markup $\mu_{i j}>\mu_{i}$, defined hereinafter as the indirect exporter's markup.

Double marginalization can be easily illustrated by assembling equations (4) and (5) in order to derive the unconditional optimal export price (in the domestic currency) for goods traded through intermediaries, which is

$$
\begin{gathered}
p_{i j}^{*}=\frac{\underbrace{\sigma-1}_{\equiv}\left[1+\frac{\eta^{*}}{\sigma \tau \epsilon \underbrace{*}_{j} \frac{\sigma-1}{\sigma-2}\left(1+\frac{\eta^{*} \varphi_{i}}{(\sigma-1) \epsilon \tau}\right) \frac{1}{\varphi_{i}}}\right]}{\underbrace{\frac{\sigma-1}{\sigma-2}\left(1+\frac{\eta^{*} \varphi_{i}}{(\sigma-1) \epsilon \tau}\right)}_{=p_{i j}} \cdot \frac{1}{\varphi_{i}}}= \\
=\underbrace{\frac{\sigma}{\sigma-2}\left(1+\frac{2 \eta^{*} \varphi_{i}}{\sigma \epsilon \tau}\right)}_{\equiv \mu_{i j}} \cdot \frac{\underbrace{1}_{\equiv \mu_{i j}^{*}}}{\varphi_{i}} .
\end{gathered}
$$

To summarize, in case of goods that are traded via intermediaries, the overall markup imposed on foreign consumers, namely

$$
\mu_{i j}^{*} \equiv \mu_{j}^{*} \cdot \mu_{i j}=\frac{\sigma}{\sigma-2}\left(1+\frac{2 \eta^{*} \varphi_{i}}{\sigma \epsilon \tau}\right)
$$

is the result of the multiplicative interaction between the indirect exporter's markup, namely ${ }^{10}$

$$
\mu_{i j} \equiv \frac{\sigma-1}{\sigma-2}\left(1+\frac{\eta^{*} \varphi_{i}}{(\sigma-1) \epsilon \tau}\right)
$$

and the intermediary's markup, namely

$$
\mu_{j}^{*} \equiv \frac{\sigma}{\sigma-1}\left(1+\frac{\eta^{*}}{\sigma \tau \epsilon p_{i j}}\right)=\frac{\sigma \epsilon \tau+2 \eta^{*} \varphi_{i}}{(\sigma-1) \epsilon \tau+\eta^{*} \varphi_{i}}
$$

which is obviously positive and larger than one 11 A series of theoretical results then follows from equations (2) to (6); formal proofs are reported in Appendix A2 12

Result 1. The indirect exporter's markup, namely $\mu_{i j}$, is not only larger than $\mu_{i}$, i.e. the markup that the same firm applies on domestic sales, but also larger than $\mu_{i}^{*}$, that is the markup that the same firm would apply on export sales, if it were a direct exporter ${ }^{13}$

\footnotetext{
${ }^{10}$ In full analogy with the direct exporter's markup $\mu_{i}^{*}$, the indirect exporter's markup $\mu_{i j}$, is (i) increasing in firm productivity $\varphi_{i}$ and in the level of local distribution costs $\eta^{*}$; and (ii) decreasing in the real exchange rate $\epsilon$, in the level of iceberg trade $\operatorname{costs} \tau$ and in the elasticity of substitution $\sigma$.

${ }^{11}$ This fact is easily proved by expressing the intermediary's markup as $\mu_{j}^{*}=1+\frac{\epsilon \tau+\eta^{*} \varphi_{i}}{(\sigma-1) \epsilon \tau+\eta^{*} \varphi_{i}}$, where the second element of this sum is necessarily positive, given $\sigma>1, \epsilon \tau>0$ and $\eta^{*} \varphi_{i}>0$ by construction.

${ }^{12}$ Notice that such results involve a comparison among markups; as far as the latter do not show up in standard transaction-level trade data, all these propositions are therefore not directly testable on our data.

${ }^{13}$ Result 1 is a direct implication of double marginalization. The additional markup charged by the intermediary firm raises the export price of the variety and reduces the quantity sold into the foreign market. By internalizing this, the indirect exporter will raise its own markup as compared to the one that would be applied if the same product were exported directly, thereby extracting more of the surplus of the intermediary.
} 
Result 2. The indirect exporter's markup, namely $\mu_{i j}$, is also larger than the intermediary's markup on the same goods, namely $\mu_{j}^{*}$.

Result 3. The overall markup charged on foreign consumer in the case of goods exported through intermediaries, namely $\mu_{i j}^{*}$, is larger than the markup imposed in the case of goods traded directly, namely $\mu_{i}^{*} 14$

A further clarification on the assumption of double marginalization is needed. A well established literature on industrial organization shows that firms engaged in a vertical relationship might seek to get rid of the inefficiency associated with double marginalization by means of a two part tariff (TPT), which can reproduce, under vertical separation, the same outcome of the vertically integrated firm. However, in the case of export intermediation, the TPT in its traditional version -which leaves the intermediary with zero profits- cannot be applied. Indeed, the downstream firm (the intermediary, in this context), which is the one to pay the cost of entry in the overseas market, necessarily requires a margin to operate. With this in mind, one could expect intermediaries and indirect exporters to engage in Nash bargaining over the extra-profit arising from the elusion of double marginalization. Nevertheless, in this framework intermediaries should have a relatively higher bargaining power, because they are both relatively less with respect to indirect exporters and less committed to exporting a given variety. For these reasons, we do not expect indirect exporters to propose a TPT to start with, and double marginalization might prevail.

\subsection{Export price and export value elasticities to exchange rate movements}

The different pricing structure that characterizes the two modes of export (the direct mode and via wholesalers) bears relevant implications as regard to the margins of adjustment of firms in the event of external shocks. In particular, in this paper we focus on adjustments to exchange rate movements. In this respect, there is a set of predictions, which can be derived from equations (2) and (6), that specifically refers to the different export-price elasticity to RER movements of goods traded directly and goods traded via intermediaries. All these predictions can be directly tested using our data.

For goods that are exported directly by the producers, the export price elasticity with respect to the RER turns out to be

$$
E_{p_{i}^{*} ; \epsilon}=-\frac{\eta^{*} \varphi_{i}}{\sigma \epsilon \tau+\eta^{*} \varphi_{i}}
$$

Given $\eta^{*} \varphi_{i}>0$ and $\sigma \epsilon \tau>0$, both by construction, we can conclude that $-1<E_{p_{i}^{*} ; \epsilon}<0$, which identifies a first testable prediction of our model.

Proposition 1. The (real) exchange rate pass-through is incomplete for direct exporters: if the domestic currency appreciates (depreciates), manufacturing firms will reduce (increase) their markup -and therefore the price in domestic currency-applied on direct-export sales.

\footnotetext{
${ }^{14}$ Given equation $(6)$, Result 3 directly follows from Result 2 : given $\mu_{i j}>\mu_{i}^{*}$ and $\mu_{j}^{*}>1$, then it necessarily holds that $\mu_{i j}^{*} \equiv \mu_{i j} \mu_{j}^{*}>\mu_{i}^{*}$.
} 
For goods exported by intermediaries, the export price elasticity with respect to the RER is instead

$$
E_{p_{i j}^{*} ; \epsilon}=-\frac{2 \eta^{*} \varphi_{i}}{\sigma \epsilon \tau+2 \eta^{*} \varphi_{i}}
$$

which implies, also in this case, $-1<E_{p_{i j}^{*} ; \epsilon}<0$. Hence, we can derive a second testable prediction.

Proposition 2. The (real) exchange rate pass-through is incomplete also for intermediary exporters: if the domestic currency appreciates (depreciates), the final export price set by the intermediary firm will decrease (increase).

Based on a simple comparison between (7) and (8), it is straightforward to show that

$$
\left|E_{p_{i j}^{*} ; \epsilon}\right|=\frac{2 \eta^{*} \varphi_{i}}{\sigma \epsilon \tau+2 \eta^{*} \varphi_{i}}>\frac{\eta^{*} \varphi_{i}}{\sigma \epsilon \tau+\eta^{*} \varphi_{i}}=\left|E_{p_{i}^{*} ; \epsilon}\right|
$$

The above inequality holds as far as $2\left(\sigma \tau \epsilon+\eta^{*} \varphi_{i}\right)>\sigma \tau \epsilon+2 \varphi \eta^{*}$, a condition which is always verified under our restrictions on the model parameters ${ }^{15}$ A third testable prediction then follows.

Proposition 3. Because of the combination of two price adjustment mechanisms, the export price elasticity with respect to real exchange rate movements is always larger for goods traded through intermediaries, rather than for goods traded directly.

As a theoretical speculation, it is worth noticing that, for goods exported by intermediaries, the result of incomplete pass-through originates from two different price adjustments. On one hand, in the event of exchange rate movements, the indirect exporter adjusts its markup $\mu_{i j}$ over the marginal cost of production when selling product $i$ to intermediary $j$. On the other hand, $j$ also adjusts its own margin $\mu_{j}^{*}$ over the procurement price.

To shed light on the relative contribution of these two changes on the overall price adjustment along the intermediary channel, we compute the elasticity to the RER of both the indirect exporter's and the intermediary's markups. In particular, the elasticity of the indirect exporter's markup is

$$
E_{\mu_{i j} ; \epsilon}=-\frac{\eta^{*} \varphi_{i}}{(\sigma-1) \tau \epsilon+\eta^{*} \varphi_{i}}
$$

It can be easily proved that $0<\left|E_{\mu_{i j} ; \epsilon}\right|<1$; moreover, $\left|E_{\mu_{i j} ; \epsilon}\right|$ is increasing in $\varphi_{i}$, which means that more productive firms will adjust their markup to a larger extent than less productive firms, consistently with the findings of Berman et al. (2012). 16

The corresponding elasticity of the intermediary's markup is instead

$$
E_{\mu_{j}^{*} ; \epsilon}=-\frac{(\sigma-1) \epsilon \tau \eta * \varphi_{i}}{\left[(\sigma-1) \epsilon \tau+\eta^{*} \varphi_{i}\right]\left[\sigma \epsilon \tau+2 \eta^{*} \varphi_{i}\right]} .
$$

\footnotetext{
${ }^{15}$ Notice that, for both the export modes, the extent of the price adjustment -i.e. the absolute value of the export price elasticity with respect to the RER- is always (i) increasing in firm productivity and in the level of local distribution costs; and (ii) decreasing in the real exchange rate, in the elasticity of substitution and in the level of iceberg costs.

${ }^{16}$ In particular, this elasticity is negative since $\sigma>1$ and $\eta^{*} \varphi_{i}>0$ necessarily imply $(\sigma-1) \epsilon \tau>0 ;$ notice also that, for $\varphi_{i}$ that goes to $+\infty$, the limit of $E_{\mu_{i j} ; \epsilon}$ is -1 .
} 
The restrictions on parameters ensure that, also in this case, $0<\left|E_{\mu_{j}^{*} ; \epsilon}\right|<1$. At odds with the former case, however, $\left|E_{\mu_{j}^{*} ; \epsilon}\right|$ is a bell shaped function of $\varphi_{i}$ : it first increases with $\varphi_{i}$, then it reaches a peak at some value less than one, and eventually starts declining, approaching zero for $\varphi_{i} \rightarrow \infty$.

Given the two elasticities, we can easily prove that

$$
\left|E_{\mu_{i j} ; \epsilon}\right|>\left|E_{\mu_{j}^{*} ; \epsilon}\right|
$$

the fundamental condition for this inequality to hold (with all the parameters of the model that are positive) being $\sigma>1$, in line with our assumptions. Inequality (9) implies that most of the overall change in the export prices along the intermediary export channel is due to the indirect exporter's response to the RER movement. In light of Result 2, the producer of good $i$ has a larger margin than intermediary $j$ for adjusting the price to the external shock, which implies that, in principle, most of the overall price adjustment is represented by a change in the indirect exporter's markup, namely $\mu_{i j}$, rather than in the intermediary's markup, i.e. $\mu_{j}^{*}$.

We now turn our attention to the export value elasticity to (real) exchange rate movements. Consider first the sales of a direct exporter $i$, namely $x_{i}^{*} \equiv p_{i}^{*} q_{i}^{*}$, where $p_{i}^{*}$ is given by equation (2), whereas $q_{i}^{*}=A^{*} \cdot\left(\widetilde{p}_{i}^{*}\right)^{-\sigma}=A^{*} \cdot\left(\tau \varepsilon p_{i}^{*}+\eta^{*} w^{*}\right)^{-\sigma}$. The direct export sales elasticity to the RER, namely $\epsilon$, can be proved to be

$$
E_{x_{i}^{*} ; \epsilon}=-\frac{\sigma \epsilon \tau}{\epsilon \tau+\eta^{*} \varphi_{i}}-\frac{\eta^{*} \varphi_{i}}{\sigma \epsilon \tau+\eta^{*} \varphi_{i}}\left[\frac{\sigma}{\sigma-1} \frac{w^{*}\left(\epsilon \tau+\eta^{*} \varphi_{i}\right)}{\varphi_{i}}\right]^{-\sigma},
$$

which is clearly negative (i.e. real appreciation always reduces the direct exporters' sales abroad).

The export sales of intermediary $j$ are instead $x_{i j}^{*} \equiv p_{i j}^{*} q_{i j}^{*}$, where $p_{i j}^{*}$ is given by equation (6), while $q_{i j}^{*}=A^{*} \cdot\left(\widetilde{p}_{i j}^{*}\right)^{-\sigma}=A^{*} \cdot\left(\tau \varepsilon p_{i j}^{*}+\eta^{*} w^{*}\right)^{-\sigma}$. The intermediary exports elasticity to the RER is

$$
E_{x_{i j}^{*} ; \epsilon}=-\frac{\sigma \epsilon \tau}{\epsilon \tau+\eta^{*} \varphi_{i}}-\frac{2 \eta^{*} \varphi_{i}}{\sigma \epsilon \tau+2 \eta^{*} \varphi_{i}}\left(\frac{\sigma}{\sigma-2} \frac{w^{*}\left[\epsilon \tau+\eta^{*} \varphi_{i}\right]}{\varphi_{i}}\right)^{-\sigma}
$$

which, again, is certainly negative (i.e. real appreciation always reduces intermediaries' exports).

A simple comparison among the two above elasticities reveals that

$$
\left|E_{x_{i}^{*} ; \epsilon}\right|>\left|E_{x_{i j}^{*} ; \epsilon}\right|
$$

which leads to the following proposition

Proposition 4. As a result of the lower degree of exchange rate pass-through that characterizes the intermediary export channel, the value of export transactions at the firm-product-country level is less responsive to RER for trade intermediaries than for direct exporters.

Notice that this theoretical result is consistent with the main finding of Bernard et al. (2015), that is, the larger the share of intermediaries' exports in a given destination, the smaller the fall in exports, following RER appreciations 17

\footnotetext{
${ }^{17}$ The condition for 10 to hold is that $\frac{2 \eta^{*} \varphi_{i}}{\epsilon \tau}>\sigma \frac{2(\sigma-2)^{\sigma}-(\sigma-1)^{\sigma}}{(\sigma-1)^{\sigma}-(\sigma-2)^{\sigma}}$, which is always verified, since the left-hand side of this inequality is certainly positive, while the left-hand side is negative. Indeed, $\sigma$ is positive by assumption, $(\sigma-1)^{\sigma}-(\sigma-2)^{\sigma}>0$ for $\sigma>1$ and $2(\sigma-2)^{\sigma}-(\sigma-1)^{\sigma}<0$ for $\sigma>1$.
} 


\subsection{Productivity cut-offs and extensive margin adjustments to exchange rate movements}

In section 3.2 we have shown that, in the event of exchange rate movements, different types of exporters adjust their export prices to a different extent. Hence, the shock is proved to have a heterogeneous impact on the intensive margin of trade, depending on whether intermediaries are involved into the exchange or not. In this Section, instead, we focus on the adjustment that takes place at the extensive margin.

This point relates to the mechanisms according to which firms select their mode of export. In this regard, our model generates a standard productivity-sorting pattern: the most productive firms export directly; firms with intermediate levels of productivity resort on intermediaries, whereas the least productive firms only serve the domestic market. This is the same pattern that emerges in Ahn et al. (2011) and Felbermayr and Jung (2011) and empirically verified also by Grazzi and Tomasi (2016). In Appendix A3 we report anyway a formal proof of this sorting behavior, to show how the conditions to be imposed for the emergence of this pattern in our model generalize those to be imposed in a simpler setting with no local distributions costs.

Consider now the two export cut-offs that emerge in the presence of intermediaries. The first is the direct-export productivity cut-off, which corresponds to

$$
\varphi_{X^{d i r}} \equiv \frac{\tau \epsilon}{\left(\frac{\phi A^{*}}{\epsilon(1-\lambda) f_{X}}\right)^{\frac{1}{\sigma-1}}-w^{*} \eta^{*}}, \text { where } \phi \equiv \frac{(\sigma-1)^{\sigma-1}-(\sigma-2)^{\sigma-1}}{\sigma^{\sigma} \delta} .
$$

All manufacturing firms with productivity higher than $\varphi_{X}$ dir will then find optimal to export directly. The second is the indirect-export productivity cut-off, that is

$$
\varphi_{X^{i n d}} \equiv \frac{\tau \epsilon}{\left(\frac{\chi A^{*}}{\epsilon \lambda f_{X}}\right)^{\frac{1}{\sigma-1}}-w^{*} \eta^{*}}, \text { where } \chi \equiv \frac{(\sigma-2)^{\sigma-1}}{\sigma^{\sigma} \delta} .
$$

Hence, all manufacturing firms with productivity lower than $\varphi_{X^{i n d}}$ will do not engage in any export activity (even indirectly) and will simply serve the domestic market; those with productivity higher than $\varphi_{X^{i n d}}$ will have instead positive profits from indirect export sales and will therefore reach the foreign markets by means of an intermediary. Nevertheless, given $\varphi_{X}$ dir $>\varphi_{X^{i n d}}$, the most productive firms, i.e. those with productivity higher than $\varphi_{X \text { dir }}$, will always prefer to manage directly their exports, rather than going for the intermediary export channel.

As shown in Appendix A3, the condition to be imposed for the emergence of this pattern is that the fixed cost of accessing trade intermediation services is small enough as compared to the fixed cost of direct entry into the foreign market ${ }^{18}$ If this were not the case, indirect exporters would not be saving enough on the fixed cost of exports to compensate for the implicit cost of double marginalization (which raises the export price, reducing quantities sold abroad); exports through intermediaries would then be viable only for those manufactures that are productive enough to remain competitive in spite of the additional markup imposed by the export intermediary.

\footnotetext{
${ }^{18}$ Indeed, in Appendix A3 we impose a restriction on $\lambda$, i.e. the relative size of the fixed cost of contracting an intermediary, namely $f_{X^{d i r}}$, vis-à-vis the cost of direct entry in the foreign market, namely $f_{X^{d i r}}=f_{X}$.
} 
According to equations (11) and (12), both the export cut-off levels depend positively on the RER, namely $\epsilon=\varepsilon w^{*} / w$ (with $w=1$ ); a real appreciation thus implies an increase in the critical level of productivity for either direct or indirect exporting.

With some simple algebra, the elasticity of the direct-export cut-off to RER movements can be proved to be

$$
E_{X^{d i r} ; \epsilon}=1-\frac{\frac{1}{\sigma-1}\left(\frac{\left(w^{*}\right)^{-\sigma} \phi A^{*}}{\epsilon(1-\lambda) f_{X}}\right)^{\frac{1}{\sigma-1}}}{\left(\frac{\left(w^{*}\right)^{-\sigma} \phi A^{*}}{\epsilon(1-\lambda) f_{X}}\right)^{\frac{1}{\sigma-1}}-\eta^{*}}
$$

whereas the corresponding elasticity for the indirect-export cut-off is

$$
E_{X^{i n d} ; \epsilon}=1-\frac{\frac{1}{\sigma-1}\left(\frac{\left(w^{*}\right)^{-\sigma} \chi A^{*}}{\epsilon \lambda f_{X}}\right)^{\frac{1}{\sigma-1}}}{\left(\frac{\left(w^{*}\right)^{-\sigma} \chi A^{*}}{\epsilon \lambda f_{X}}\right)^{\frac{1}{\sigma-1}}-\eta^{*}}
$$

with both these elasticities being positive by construction, provided that $\sigma>2$.

The same circumstances under which the usual sorting pattern emerges, also ensure that

$$
E_{X^{i n d} ; \epsilon}>E_{X^{d i r} ; \epsilon}
$$

that is, the indirect-export productivity cut-off is more elastic to RER movements than the directexport cut-off. Hence, in the event of a real appreciation (depreciation), the cut-off level for indirect export shifts upward (downward) relatively more than the cut-off for direct export (see Appendix A4 for a formal proof).

With some loss of generality, if we introduce a mild assumption on the firm productivity distribution $G(\varphi)$, then the condition in 13 delivers a new testable prediction on the effects of a RER movement, particularly on the change in the number of varieties that are traded directly and through an intermediary. More specifically, consider the case in which the density of $\varphi$ is monotonically (weakly) decreasing, such as in the case of uniform or Pareto distribution, the latter being the most commonly used in the trade literature on monopolistic competition and heterogeneous firms 19 A new proposition then follows.

Proposition 5. As far as the density of $\varphi_{i}$ is monotonically (weakly) decreasing, such as in the case of uniform or Pareto distribution, then the measure of varieties that intermediaries drop in response to real appreciations is larger, on aggregate, then the measure of varieties discarded from direct exporters.

\footnotetext{
${ }^{19}$ In this class of models, assuming CES preferences and Pareto productivity largely increases the model tractability (see Chaney, 2008) but implies that also firm sales are Pareto-distributed. This is challenged by the empirical evidence, which seems to be more in favor of a log-normal distribution (Head et al. 2014, and Eaton et al. 2011). However, the Pareto matches well the upper tail of the observed sales distribution, where most of the global trade actually occurs (exporting firms are typically both larger and more productive). Moreover, a recent work of Mrázová et al. (2015) shows that, in order to explain sales and markups distributions, the assumption on the demand function is far more relevant than the choice between a Pareto and a log-normal distribution for firm productivity. For all these reasons the class of monotonically (weakly) decreasing distributions, hence including Pareto, appears appropriate.
} 
An appreciation of the domestic currency makes it more difficult to sell national products abroad, increasing the minimum level of productivity which is required for making exports a profitable activity. This is true for both the direct and the indirect mode of export. In the aftermath of the currency appreciation, the least productive among the indirect exporters will now locate below the cut-off level for indirect entry and their variety will not be traded any longer. This identifies a first range of varieties, namely those that are dropped by the intermediary firms. At the same time, also manufacturers whose productivity is just above the cut-off for direct-entry will not be able to export directly anymore; hence they will need to resort to intermediaries to profitably reach the foreign destination. This identifies a second set of varieties, namely those that will switch from direct export to being traded through intermediaries.

If the wholesalers were characterized by an optimal scope, as in the model of Akerman (forthcoming), then the two sets of varieties would be quantitatively equivalent: in the event of a currency appreciation, intermediaries would get rid of their marginal varieties only to the extent necessary to create room in their export baskets for the varieties discarded from the direct export channel. Nevertheless, if the density of firm productivity is monotonically (weakly) decreasing in the level of productivity $\varphi$, then the condition in (13) ensures that the number of varieties dropped by intermediaries is bigger than the number of varieties that is now added to their product portfolio. As a result, in our model not only the direct but also the indirect mode of export features an (aggregate) extensive margin of adjustment to external shocks, the validity of this prediction being directly testable on our data.

\section{Data and empirical evidence}

\subsection{Trade and firm-level data}

In order to test the propositions put forth in the model, we use two data set collected by the Italian statistical office (ISTAT): Statistiche del Commercio Estero (COE), and Archivio Statistico Imprese Attive (ASIA) 20

COE contains all cross-border transactions (both exports and imports) of Italian firms over the period 2000-07. For all export flows defined at the firm-product-destination level we observe both annual values and quantities expressed respectively in euros and in kilograms ${ }^{21}$ Products are defined as six-digit category in the Harmonized System (HS6). Because some product categories are assigned different HS6 product codes at different points in time, we use concordance tables provided by Eurostat to harmonize the classifications to the 2002 version. COE data are used to obtain the unit-values Unit Value $_{f p t}$ of the exported varieties as the ratio of export values to export quantities, where the subscripts $f, c, p$ and $t$ respectively identify firms, HS6 product

\footnotetext{
${ }^{20}$ The database has been made available for work after careful screening to avoid disclosure of individual information. The data were accessed at the ISTAT facilities in Rome.

${ }^{21}$ ISTAT collects data on trade based on transactions. The European Union sets a common framework of rules but leaves some flexibility to member states. A detailed description of requirements for data collection on trade in Italy is provided by Bernard et al. (2015). Although only annual values which exceeds a threshold are reported in the dataset, this is unlikely to affect our analyses as the transactions collected cover about $98 \%$ of the total Italian trade flows (http://www.coeweb.istat.it/default.htm).
} 
classes, destination countries and years.

Using the common firm ID, we link the firm-level export data to ISTAT's registry of active firms (ASIA) which provides the sectoral classification of business required to identify manufacturing and wholesale businesses. We employ the ATECO industrial classification, which is derived from NACE Rev. 1.1, at five digits. More in detail, as in Bernard et al. (2015), we classify firms in sectors from 151 to 372 as manufacturers and firms in sectors from 501 to 519 (with the exclusion of 502 which concerns the activity of repair of motor vehicles) as wholesalers or intermediaries (notice that, throughout this paper, the two terms are used interchangeably). The combined data set that result from matching COE to ASIA is not a sample but includes all active firms and is our preferred dataset for testing the model.

In 2000 manufacturers were responsible for the larger share (85\%) of Italian aggregate exports, intermediaries accounted for around $10 \%$, retailers for below than $1 \%$ and other firms for the remaining $4 \%$. The share of exports generated by intermediaries was slightly but constantly growing from $9.85 \%$ in 2000 to $11.27 \%$ in 2007 . In 2000 the $10 \%$ export share of intermediaries was due to $26 \%$ of Italian exporters classified as wholesalers, whether the $85 \%$ export share of manufacturers was generated by $57 \%$ of Italian exporters recorded as manufacture exporters (Bernard et al. 2015). Intermediaries exporters are on average smaller than manufacturers that sell abroad but this difference largely disappears when considering exports per employee. Moreover, both exporting intermediaries and manufacturers sell several products to each destination but the former are active in a wider range of products compared to similarly-sized manufacturers. Detailed descriptive evidence on the characteristics of wholesalers and manufacturing exporters, also focusing on product and geographic diversity, is available in Bernard et al. (2011).

The transaction-level data is used to test the propositions put forth in the theoretical setting. Notice that in our data, most of the manufacturing firms that export directly tend to reach the foreign market with more than one product category. In this respect, the implicit assumption of our model is that manufacturing firms can potentially engage in producing many varieties of the final good, but all these varieties correspond to businesses that are independent from each other. Hence, we consider the product-specific component of the fixed cost of exporting as the relevant one, as compared to the other component, represented by a standard firm-level sunk cost ${ }^{22}$

\subsection{Empirical evidence on price and exports elasticities to the RER}

In this section we test the validity of our model with respect to firms' price and exports adjustments following a change in the RER. We focus on Propositions 1 to 3 that relate the export price adjustment in the event of RER movements to the mode of export of the different products, and

\footnotetext{
${ }^{22}$ In principle, neither assuming a pure firm-specific or product-specific formulation for the fixed cost of export appears as fully satisfactory: under firm-specific costs, in fact, it would be hard to justify why multi-product firms tend to react to external shock (such as RER movements) by keeping exporting only their core products and dropping the marginal products in their portfolio, as documented in Chatterjee et al. (2013). To clarify this point, consider a toy model in which firm $i$ exports to some given destination three different products, say $a, b$ and $c$, in descending order of productivity. If the fixed cost of entry in the foreign market were product-specific, in the aftermath of a currency appreciation firm $i$ might find convenient to keep exporting product $a$ and $b$, and drop $c$. At odds, in case of firms-specific fixed costs, having sunk the cost for varieties $a$ and $b$, firm $i$ would have no reason to drop $c$, thereby giving up on positive profits (even if small) from the sale of $c$ abroad.
} 
on Proposition 4, which considers a firm's export sales adjustment following RER movements. Do intermediary exporters have indeed different price and exports responses to exchange rates than manufacturing exporters?

To explore the sensitivity of the firm's export price response to annual movements of the exchange rate for a given country-product pair, we explore information on unit values of the exported products and we consider the following equation

$$
\Delta \ln \text { UnitValue }_{f p t}=\beta_{0}+\beta_{1} D_{f t}^{W}+\beta_{2} \Delta \ln R E R_{c t}+\beta_{3} \Delta \ln R E R_{c t} * D_{f t}^{W}+d_{j}+\nu_{f p c t},
$$

where $\Delta \ln$ UnitValue $_{\text {fpct }}$ is annual difference in the unit value of product $p$ in country $c$ by individual firm $f$ between time $t$ and $t+1$, whereas $d_{j}$ indicates a set of fixed effects. We denote with $D_{f t}^{W}$ the dummy variable which identifies $f$ as an intermediary firm ( $W$ stands for wholesaler). The (log) real exchange rate is denoted as $\ln R E R_{c t}$, and is here defined as the nominal Italian exchange rate, expressed as the number of foreign currency units per home currency unit (i.e. $E R_{c t}$ ), multiplied by the ratio between the domestic consumer price index, and the corresponding index abroad (i.e. $C P I_{t} / C P I_{c t}$ ) ${ }^{23}$ An upward (downward) movement of the RER therefore represents an appreciation (depreciation) of the domestic currency. Real exchange rates are measured using data from the International Financial Statistics database (IMF, 2010). In the above equation, both the dependent variable and RER are defined as annual differences.

The extent to which exchange rate variations are transmitted into consumer prices can be computed as ERPT $=1-\beta_{2}$ where $\beta_{2}$ is the coefficient of $R E R_{c t}$ in regressions on Unit Value fcpt. Accordingly, if exporters do not adjust their export prices in response to exchange rate variations then $\beta_{2}=0$ and the ERPT is perfect. On the contrary, the closer is $\beta_{2}$ to -1 the greater is the offsetting adjustment of export prices to neutralize ERPT into consumer prices. We expect a negative sign on both $\beta_{2}$ and $\beta_{3}$. While the first coefficient measures the pricing to market of manufacturing firms, the second captures the heterogeneity of pricing strategies with respect to the mode of exports. According to Proposition 3 of our model, intermediaries decrease more their export price following a depreciation.

To test the sensitivity of the firm's export values to annual movements of the exchange rate for a given country-product pair, we use the same reduced-form strategy

$$
\Delta \ln X_{f c p t}=\beta_{0}+\beta_{1} D_{f t}^{W}+\beta_{2} \Delta \ln R E R_{c t}+\beta_{3} \Delta \ln R E R_{c t} * D_{f t}^{W}+d_{j}+\nu_{f p c t},
$$

where $X_{f p c t}$ denotes the export value of product $p$ in country $c$ by firm $f$. Following Proposition 4 of our model the coefficient on the interaction term, $\beta_{3}$, should be positive: the export value elasticity to real exchange rate changes should be lower for intermediary exporters.

Columns 1 and 2 of Table 1 report the results from regression model 14, while columns 3 and 4 show the estimates of equation 15 . We cluster standard errors at the destination-year level in order to allow for correlation of the error terms across destination-year but the results are robust

\footnotetext{
${ }^{23}$ We use annual averages of the monthly official exchange rate, that can be either the rate determined by national authorities or the rate determined in the legally sanctioned exchange market. Using a wholesale price index to construct the RER reduces the number of countries in the sample, but does not affect the main results. See Table B1 in Appendix B for the results of regression 14 using the WPI.
} 
Table 1: Firm's unit value and exports elasticities to exchange rate movements

\begin{tabular}{lcccc}
\hline & \multicolumn{4}{c}{ Annual Differences } \\
\hline & \multicolumn{2}{c}{ ln UnitValue fcpt $^{2} \ln \mathrm{X}_{f c p t}$} \\
& $(1)$ & $(2)$ & $(3)$ & $(4)$ \\
\hline$D_{f t}^{W}$ & -0.002 & & $-0.020^{* * *}$ & \\
& $(0.001)$ & & $(0.003)$ & \\
$\ln \mathrm{RER}_{c t}$ & $-0.034^{* * *}$ & $-0.031^{* * *}$ & $-0.316^{* * *}$ & $-0.376^{* * *}$ \\
& $(0.011)$ & $(0.011)$ & $(0.092)$ & $(0.109)$ \\
\multicolumn{1}{c}{$* D_{f t}^{W}$} & $-0.021^{*}$ & $-0.030^{* *}$ & $0.069^{*}$ & $0.031^{* *}$ \\
& $(0.011)$ & $(0.013)$ & $(0.039)$ & $(0.015)$ \\
& & & & \\
Country FE & Yes & Yes & Yes & Yes \\
Year FE & Yes & Yes & Yes & Yes \\
Product FE & Yes & No & Yes & No \\
Firm-Product FE & No & Yes & No & Yes \\
Clustering Country-Year & Yes & Yes & Yes & Yes \\
& & & & \\
Adj R-squared & 0.003 & -0.011 & 0.004 & -0.010 \\
Observations & 4008339 & 4008339 & 4008339 & 4008339 \\
\hline
\end{tabular}

Note: Table reports the results of regressions at the firm-product-country level, obtained by using data on export values, quantities and unit values between 2000 and 2007. The dependent variables and the real exchange rates (RER) are defined as annual differences. $D_{f t}^{W}$ is a dummy for intermediaries; $* D_{f t}^{W}$ is the interaction term with real exchange rates in annual differences. Robust standard errors clustered at country-year level are reported in parenthesis below the coefficients. Asterisks denote significance levels (***: $\mathrm{p}<1 \%$; *: $\mathrm{p}<5 \%$; : $\mathrm{p}<10 \%$ ). Source: Our elaboration on Italian micro-data.

to alternative treatments of the error terms, such as clustering by destination. In columns 1 and 3 we show the estimated coefficient from a specification that includes year, country and product fixed effects that control for time trends and shocks that affect all firms exporting the same HS6 product and serving the same destination. Columns 2 and 4 report the results from a specification including year, destination and firm-product fixed effects which takes into account also possible idiosyncratic firm-product attributes that may be correlated with the evolution of export value, prices or quantities.

Results of columns 1 and 2 represent a direct test of Proposition 1 to 3 of the theoretical framework we propose here. Unit values decrease both for manufacturing and intermediaries, which is coherent to what put fort in Proposition 1 and 2 . The coefficient on $R E R, \beta_{2}$, reports the average elasticity of export prices to RER variations for manufacturing firms. The exchange rate elasticity of export prices for these firms is estimated to be on a range between -0.031 and -0.034, which implies an exchange rate pass-through into the import prices of about $0.96{ }^{24}$ The interaction term between exchange rates and a dummy for wholesaler $D_{f t}^{W}$ reveals that price adjustment is significantly larger for intermediaries, as predicted by Proposition 3 of our model. According to column 1, the estimated exchange rate elasticity of wholesalers' export prices is approximately -0.055, which implies an exchange rate pass-through into the import prices of about 0.95 . When

\footnotetext{
${ }^{24}$ Using the same dataset, Bernini and Tomasi (2015) find an exchange rate pass-through into the import prices of about 0.97. Using similar micro-level data for French exporters Berman et al. (2012) find an exchange rate passthrough to import prices abroad of around 0.88, while in Chatterjee et al. (2013) the producer price elasticity for Brazilian exporters is estimated to be of approximately 0.23 ( $77 \%$ of pass-through).
} 
Table 2: Firm's unit value and exports elasticities to exchange rate movements: robustness checks

\begin{tabular}{|c|c|c|c|c|}
\hline & \multicolumn{4}{|c|}{ Annual Differences } \\
\hline & $\begin{array}{l}\text { ln UnitValue }{ }_{f c p t} \\
\text { (1) }\end{array}$ & $\begin{array}{l}\text { ln UnitValue }{ }_{f c p t} \\
(2)\end{array}$ & $\begin{array}{c}\ln \mathrm{X}_{f c p t} \\
(3)\end{array}$ & $\begin{array}{c}\ln \mathrm{X}_{f c p t} \\
(4)\end{array}$ \\
\hline $\ln \mathrm{RER}_{c t}$ & $-0.031^{* *}$ & $-0.026^{* *}$ & $-0.163^{* * *}$ & $-0.226^{*}$ \\
\hline & $(0.017)$ & $(0.016)$ & $(0.035)$ & $(0.107)$ \\
\hline$* D_{f t}^{W}$ & $-0.034^{* *}$ & $-0.020^{* *}$ & $0.021^{* *}$ & $0.023^{*}$ \\
\hline & $(0.011)$ & $(0.010)$ & $(0.009)$ & $(0.012)$ \\
\hline$* \ln n c e_{f t}$ & $\begin{array}{c}0.001 \\
(0.004)\end{array}$ & & $\begin{array}{c}-0.091^{* * *} \\
(0.025)\end{array}$ & \\
\hline$* \ln n p c_{f c t}$ & & $\begin{array}{c}-0.009^{* * *} \\
(0.004)\end{array}$ & & $\begin{array}{r}-0.036^{* *} \\
(0.014)\end{array}$ \\
\hline $\ln n c e_{f t}$ & $\begin{array}{l}0.003^{*} \\
(0.002)\end{array}$ & & $\begin{array}{c}-0.092^{* * *} \\
(0.011)\end{array}$ & \\
\hline $\ln n p c_{f c t}$ & & $\begin{array}{l}0.003^{*} \\
(0.001)\end{array}$ & & $\begin{array}{r}-0.058^{* * *} \\
(0.006)\end{array}$ \\
\hline Country FE & Yes & Yes & Yes & Yes \\
\hline Year FE & Yes & Yes & Yes & Yes \\
\hline Firm-Product FE & Yes & Yes & Yes & Yes \\
\hline Clustering Country-Year & Yes & Yes & Yes & Yes \\
\hline Adj R-squared & 0.034 & 0.033 & -0.010 & -0.005 \\
\hline Observations & 4008339 & 3852915 & 4008339 & 3852915 \\
\hline
\end{tabular}

Note: Table reports the results of regressions at the firm-product-country level, obtained by using data on export values, quantities and unit values between 2000 and 2007. The dependent variables and the real exchange rates (RER) are defined as annual differences. $D_{f t}^{W}$ is a dummy for intermediaries; ln $n c e_{f t}$ is the (log) number of countries a firm is exporting to; $\ln n p c_{f c t}$ is the (log) number of product-countries a firm is exporting to $* D_{f t}^{W}, * \ln n c e_{f t}, * \ln n p c_{f c t}$ are the interaction terms with real exchange rates in annual differences. Robust standard errors clustered at country-year level are reported in parenthesis below the coefficients. Asterisks denote significance levels $(* * *: \mathrm{p}<1 \% ; * *: \mathrm{p}<5 \%$; *: $\mathrm{p}<10 \%$ ). Source: Our elaboration on Italian micro-data.

considering the firm-product fixed effects, column 2, the effect is slightly larger with an elasticity to RER movements of about -0.060 .

As far as the value of exports (columns 3 and 4) to a given product-country combination is concerned, we observe - as expected - a negative coefficient on $\ln R E R_{c t}$ : export values fall in response to currency appreciation. However, as predicted by Proposition 4, the coefficient on the interaction of wholesaler type and the real exchange rate is positive and significant in both columns, suggesting that exports through intermediaries are less elastic to RER as compared to direct export sales. Firms' exports fall less (8-21 percent) for intermediaries than for manufacturers when the Italian currency appreciates. This result is well in tune with Bernard et al. (2015), which report similar results at a more aggregate level.

\subsubsection{Robustness checks}

In this section we consider a set of exercises which test the robustness of our results to the inclusion of additional controls in the baseline specification. Because firm-product fixed effects provide a better control for firms' idiosyncratic attributes, they will be included in all the specifications that follow. 
Table 3: Firm's unit value and exports elasticities to exchange rate movements: with TFP interacted

\begin{tabular}{|c|c|c|c|c|}
\hline & \multicolumn{4}{|c|}{ Annual Differences } \\
\hline & $\begin{array}{l}\text { ln UnitValue } \text { f }_{c p t} \\
\text { (1) }\end{array}$ & $\begin{array}{c}\text { ln UnitValue } f c p t \\
(2)\end{array}$ & $\begin{array}{c}\ln \mathrm{X}_{f c p t} \\
(3)\end{array}$ & $\begin{array}{c}\ln \mathrm{X}_{f c p t} \\
(4)\end{array}$ \\
\hline $\ln \mathrm{RER}_{c t}$ & $-0.032^{* *}$ & 0.138 & $-0.398^{* * *}$ & $-0.619^{* * *}$ \\
\hline & $(0.014)$ & $(0.088)$ & $(0.121)$ & $(0.176)$ \\
\hline$* D_{f t}^{W}$ & $-0.063^{* *}$ & $-0.060 * *$ & $0.028^{*}$ & $0.026^{*}$ \\
\hline & $(0.029)$ & $(0.029)$ & $(0.017)$ & $(0.015)$ \\
\hline$* \ln \widehat{T F P} P_{f t-1}$ & & $\begin{array}{c}-0.035^{* *} \\
(0.013)\end{array}$ & & $\begin{array}{c}0.046 \\
(0.033)\end{array}$ \\
\hline Country FE & Yes & Yes & Yes & Yes \\
\hline Year FE & Yes & Yes & Yes & Yes \\
\hline Firm-Product FE & Yes & Yes & Yes & Yes \\
\hline Clustering Country-Year & Yes & Yes & Yes & Yes \\
\hline Adj R-squared & 0.003 & 0.003 & 0.007 & 0.007 \\
\hline Observations & 2081711 & 2081711 & 2081711 & 2081711 \\
\hline
\end{tabular}

Note: Table reports results of regressions at the firm-product-country-level, using data on export values, quantities and unit values of exported products for the period 2000-2006. The dependent and independent variables are defined as annual differences. $D_{f t}^{W}$ is a dummy for intermediaries; $* D_{f t}^{W}$ is the interacted dummy, and $* T F P_{f t}$ is the interaction term with real exchange rates in annual differences. Robust standard errors clustered at country-year level are reported in parenthesis below the coefficients. Asterisks denote significance levels $(* * *: \mathrm{p}<1 \%$; $* *$ : $\mathrm{p}<5 \%$; *: $\mathrm{p}<10 \%$ ). Source: Our elaboration on Italian micro-data.

As a first robustness check we run equations (14) and (15) by including the (log) number of countries, ln nce ft to which a firms is exporting to and its interaction with RER in order to control for the possible shift of exports to other countries in response to real exchange rate appreciation. These regressions are reported in columns 1 and 3 of Table 2, for unit value and export value respectively. Moreover, since the sunk entry-costs can be at country-product level, we include the $(\log )$ number of country-product pairs $\left(l n n p c_{f c t}\right)$ where the firm has positive exports, with the exclusion of the country under investigation, so that, even for the same firm, such variable might take different values across countries. Columns 2 and 4 of Table 2 report the results. The main results are robust across these specifications. As far as unit value is concerned, the coefficient on the interaction term remains negative and statistically significant suggesting that export price adjustment is higher (and ERPT is lower) for intermediaries.

Although the exchange rate movement can be safely considered as a shock which is exogenous to the firm, as shown for French firms in Berman et al. (2012), the firm-level adjustment might be related to some firms' characteristic such as productivity. In particular, one might argue that the different response in terms of unit values between direct exporters and intermediaries may be driven by the lack of specific controls for productivity differences across firms.

As an additional robustness check we therefore add such control. In order to perform this check, we link our Italian trade data to firm-level characteristics, retrieved from Micro.3, a dataset containing information on 148,604 Italian firms (those with more than 20 employees; 71,437 of which classified as manufacturers) for the period 1989-2006 (see Grazzi et al. 2013, for further details on the dataset). Using this data, we measure exporters' productivity by means of the total 
Table 4: Firm's export quantity elasticities to exchange rate movements

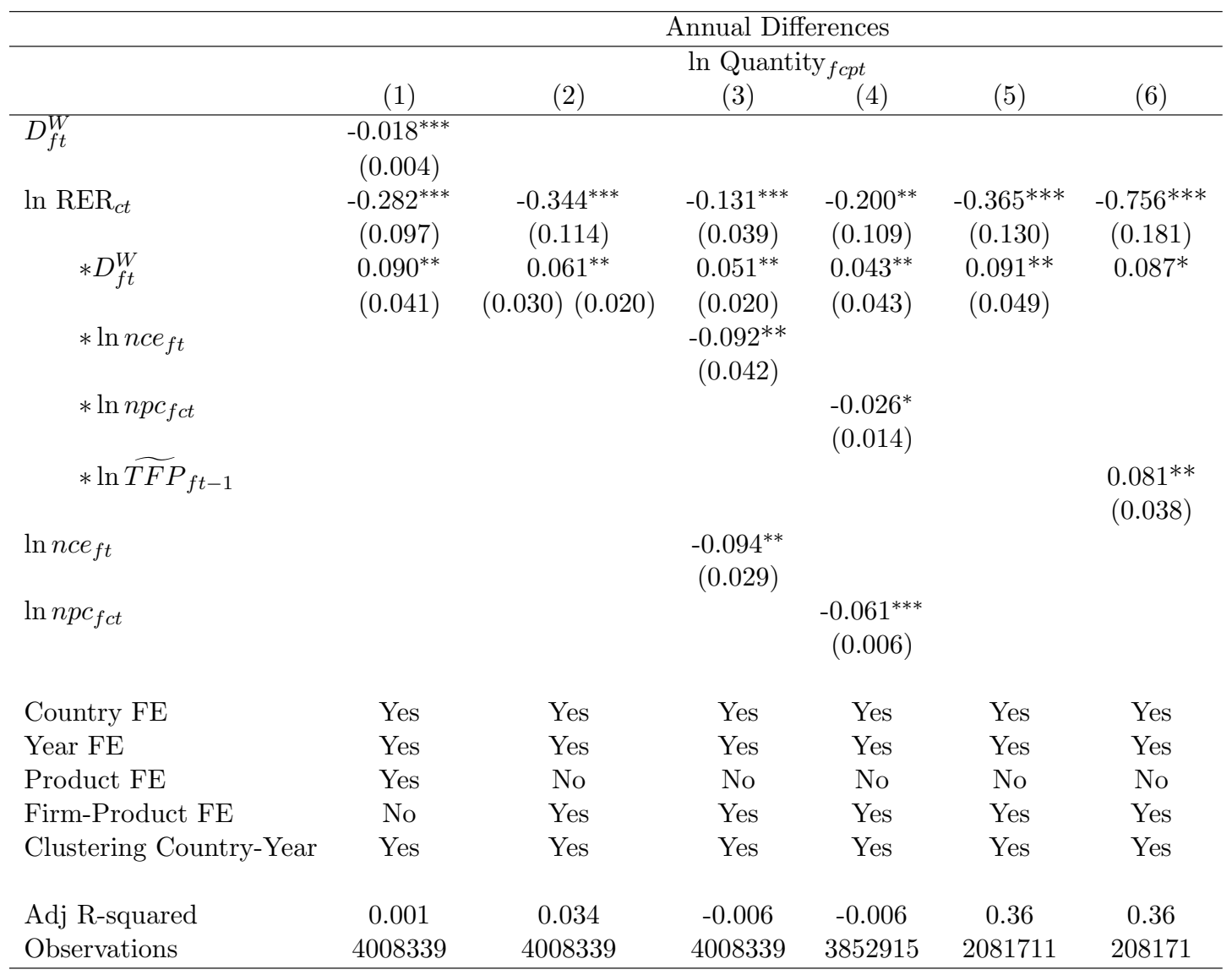

Note: Table reports the results of regressions at the firm-product-country level, obtained by using data on export values, quantities and unit values between 2000 and 2007. The dependent variables and the real exchange rates (RER) are defined as annual differences. $D_{f t}^{W}$ is a dummy for intermediaries; $* D_{f t}^{W}$ is the interaction term with real exchange rates in annual differences. Robust standard errors clustered at country-year level are reported in parenthesis below the coefficients. Asterisks denote significance levels (***: $\mathrm{p}<1 \%$; **: $\mathrm{p}<5 \%$; : $\mathrm{p}<10 \%$ ). Source: Our elaboration on Italian micro-data.

factor productivity (TFP), as computed by applying the semi-parametric estimation technique of Levinsohn and Petrin (2003). In Table B2 in Appendix B we first verify that the results of Berman et al. (2012) also hold for Italian firms.

We estimate now a slightly modified version of equations (14) and (15), augmented with the inclusion of the interacted TFP measure. Hence, the new equation to be estimated is

$$
\begin{aligned}
\Delta \ln Y_{f p c t} & =\beta_{0}+\beta_{1} D_{f t}^{W}+\beta_{2} \Delta \ln R E R_{c t}+\beta_{3} \Delta \ln R E R_{c t} * D_{f t}^{W}+ \\
& +\beta_{4} \Delta \ln R E R_{c t} * \widetilde{T F P_{f t-1}}+d_{j}+\nu_{f p c t},
\end{aligned}
$$

where $\ln Y_{f p c t}$ is the $\log$ of the dependent variable, which can be the unit value or total exports of a given product $p$ in destination $c$ by a firm $f$. We add to the baseline specification the interaction term $\Delta \ln R E R_{c t} * \widetilde{T F P}_{f t-1}$.

Linking transaction level trade data with the firm-level information contained in Micro.3 significantly reduces the number of observations available. For this reason, in Table 3 we first replicate 
our baseline model to the restricted sample (columns 1 and 3, for unit value and exports respectively), thereby checking whether the results of the regression might be driven by the selection of relatively larger firms. The restricted sample in columns 1 and 3 confirms our findings, according to which, in the event of currency appreciations, intermediaries tend to reduce their unit values more than the manufacturing exporters; hence, the pass-through along the intermediary export channel is lower, and total exports fall less. As columns 2 and 4 of Table 3 show, including the TFP variable, interacted with the annual movement of the (log) RER, does not alter these results.

To complete the empirical analysis in Table 4 we report the results of the same regressions run for unit value and total exports using as dependent variable the difference of the (log) export quantity of product $p$ in country $c$ by a given firm $f$. We note that in general, the overall adjustment in exports for direct exporters is primarily due to reduction in the quantities (80\%) rather than in unit value $(20 \%)$ of the exported products. For intermediaries, the overall adjustment turns out to be smaller, essentially because of a much smaller quantity response. This is explained by the fact that intermediaries reduce their unit values more than direct exporters: the exchange rate pass-through is therefore lower for them, and the quantities sold abroad consequently fall by less.

\subsection{Empirical evidence on the extensive margin}

Our theoretical framework also formulates that, given how productivity is distributed among manufacturing firms, we should expect that following a RER appreciation, intermediaries drop more varieties than manufacturers (see Proposition 5 in Section 3.3.

In the following, in order to test this prediction, we focus on the dropping behavior of the two categories of firms and we regress the number of varieties dropped by wholesalers and direct exporters between years $t$ and $t+1$, conditional on (real) exchange rate variations. We analyze the different dropping behavior of the two types of exporting firms by estimating the following model at the product-country level

$$
\ln \# \operatorname{Drop}_{p c t}^{W}=\beta_{0}+\beta_{1} D_{t}^{W}+\beta_{2} \Delta \ln R E R_{c t}+\beta_{3} \Delta \ln R E R_{c t} * D_{t}^{W}+\beta_{4} X_{t}^{W}+d_{j}+\nu_{p c t},
$$

where \#Drop $p_{c p t}^{W}$ is the $(\log )$ number of varieties of product $p$ exported to country $c$ in year $t$ but not in year $t+1$ by the category $W$ (either wholesalers or direct exporters). $D_{t}^{W}$ is the dummy that identifies the intermediary category, while $\Delta \ln R E R_{c t}$ is the change in the (log) real exchange rate of the Italian currency vis-a-vis the currency of country $c$, Finally, $\Delta \ln R E R_{c t} * D_{t}^{W}$ is the variable of interest, that captures whether and to what extent the intermediary category is more likely to drop varieties than manufacturing exports, following a change in RER.

To control for attributes that might be associated with the difference between dropping behavior, we include a vector of controls, denoted as $X_{t}^{W}$. As indeed shown by Bernard et al. (2011), there are significant differences between wholesaler and manufacturing exporters in terms of product and geographic diversity. To account for this, we include a proxy for the product diversification of the two category, $\ln N P_{c t}^{W}$, which is the (log) number of products exported within country $c$ at time $t$, and a proxy for their geographic diversification, $\ln N C_{p t}^{W}$, which is the (log) number of countries served with product $p$ at time $t$. We include in the regression year and product-country fixed effects 
Table 5: Number of varieties dropped in the aftermath of exchange rate movements

\begin{tabular}{|c|c|c|c|c|}
\hline & \multicolumn{4}{|c|}{$\ln \#$ Drop pct } \\
\hline & (1) & $(2)$ & $(3)$ & (4) \\
\hline \multirow[t]{2}{*}{$\Delta \ln \mathrm{RER}_{c t}$} & 0.004 & -0.007 & 0.002 & -0.023 \\
\hline & $(0.004)$ & $(0.004)$ & $(0.004)$ & $(0.020)$ \\
\hline \multirow[t]{2}{*}{$* D_{t}^{W}$} & $0.042^{* * *}$ & $0.074^{* * *}$ & $0.039^{* * *}$ & $0.043^{* * *}$ \\
\hline & $(0.007)$ & $(0.007)$ & $(0.007)$ & $(0.008)$ \\
\hline \multirow{2}{*}{$* \ln \mathrm{NC}_{p t}^{W}$} & & & & 0.004 \\
\hline & & & & $(0.003)$ \\
\hline \multirow[t]{2}{*}{$D_{t}^{W}$} & $-0.036^{* * *}$ & $0.505^{* * *}$ & $0.330^{* * *}$ & $0.330^{* * *}$ \\
\hline & $(0.005)$ & $(0.005)$ & $(0.005)$ & $(0.005)$ \\
\hline \multirow[t]{2}{*}{$\ln \mathrm{NP}_{c t}^{W}$} & $0.463^{* * *}$ & $0.448^{* * *}$ & $0.326^{* * *}$ & $0.326^{* * *}$ \\
\hline & $(0.004)$ & $(0.003)$ & $(0.003)$ & $(0.003)$ \\
\hline \multirow[t]{2}{*}{$\ln \mathrm{NC}_{p t}^{W}$} & & $0.449^{* * *}$ & $0.330^{* * *}$ & $0.330^{* * *}$ \\
\hline & & $(0.003)$ & $(0.002)$ & $(0.002)$ \\
\hline \multirow[t]{2}{*}{ Deviation $_{p c t}^{W}$} & & & $0.134^{* * *}$ & $0.134^{* * *}$ \\
\hline & & & $(0.001)$ & $(0.001)$ \\
\hline Year FE & Yes & Yes & Yes & Yes \\
\hline Product-Country FE & Yes & Yes & Yes & Yes \\
\hline Clustering Product-Country & Yes & Yes & Yes & Yes \\
\hline Adj R-squared & 0.656 & 0.688 & 0.725 & 0.725 \\
\hline Observations & 1369279 & 1369279 & 1369279 & 1369279 \\
\hline
\end{tabular}

Note: Table reports the results of regressions at product-country-category level, where category refers either to manufacturing and intermediary sector. The dependent variable $\ln \#$ Drop pct is the number of varieties of product $p$ exported to country $c$ in year $t$ but not in year $t+1 . D_{t}^{W}$ is a dummy for wholesaler sector; $\ln \mathrm{NP}_{c t}^{W} \ln N C_{p t}^{W}$ is the number of products exported within country $c$ and the number of countries served with product $p$, respectively; Deviation $_{p c t}^{W}$ measure of the relevance of product $p$ in the exports to destination $c$ for each category $W$. All variables are computed at time $t . * D_{t}^{W}$ and $* \ln N C_{p t}^{W}$ are the interaction terms with real exchange rates in annual differences. Robust standard errors in parentheses are adjusted for clustering by product-country. Asterisks denote significance levels (***: $\mathrm{p}<1 \%$; **: $\mathrm{p}<5 \%$; $: \mathrm{p}<10 \%$ ). Source: Our elaboration on Italian micro-data.

that allows to control also for the possibility that intermediaries export products to country $c$ with characteristics that make these varieties more likely to be dropped.

Columns 1 and 2 of Table 5 report the results of the regression 17, controlling for the number of products exported by wholesalers (column 1) and for the number of countries served (column 2 ). In both cases the coefficient on the interaction term, $\Delta \ln R E R_{c t} * D_{t}^{W}$, suggests the number of varieties dropped by intermediaries is higher than that of direct exporters in the aftermath of an exchange rate appreciation. In line with Proposition 5 of our model, the measure of varieties that intermediaries drop in response to a real appreciation is larger, on aggregate, than the measure of varieties discarded from direct export. Indeed, external shocks, such as changes in tariffs or exchange rates, have different effects on intermediaries and manufacturers in terms of extensive margin 25

This differential persists even when we control, in column 3 , for the relevance of product $p$ in the exports to destination $c$ for each category $W$, Deviation $n_{p c t}^{W}$. This is computed by taking

\footnotetext{
${ }^{25}$ Even if not explicitly taken into account in our model, this result is also consistent with manufacturers having a greater commitment to their products than intermediary firms.
} 
the difference between the (log) exports of product $p$ in $c$ at time $t$ for the category $W$, and the corresponding (log) average over all the products exported in $c$ by the relative category. Finally, in column 4 we add the interaction term with the number of countries served with product $p$ in order to control for the possible shift of exports to other countries in response to real exchange rate appreciation. The results are robust to this alternative specification.

\section{Conclusion}

This paper contributes to the growing literature on trade intermediaries both by providing new facts at the micro-level and by offering a theoretical framework able to account for most of the evidence available to date. Previous works have shown that export intermediaries are relevant at the micro level, as they offer an affordable mode of export to smaller and less productive firms, as well as at the aggregate level, where their presence contributes to generate more stable trade flows.

In this work, we provide a theoretical setting that accommodates for the standard results of the literature. Most notably, introducing an intermediary sector enables firms that are not as productive to directly export, to profitably access international trade through intermediaries. In addition, we investigate through which margins - and to what extent - intermediaries are able to adjust following an exogenous shock such as a real exchange rate movement, so that in the aggregate they appear to be less responsive. Our model postulates that due to the pricing mechanism, which takes the form of double marginalization for goods exported via intermediaries, and due to local distribution costs, export prices (as proxied by unit values) charged by intermediaries are more responsive to real exchange rate movements. The lower exchange rate pass-through of intermediaries is also closely related to smaller reactions to RER movements of the value of export transactions handled by intermediaries, as compared to direct exporters. Both findings are tested on the universe of Italian export transactions at the firm-product-country level and are largely supportive of our theory.

However an exogenous shock, such as a change in RER, affects not only the intensive margin, but also the access to export or, put it differently, the (aggregate) extensive margin. In particular, in the event of a negative shock, we shall expect that some of the "marginal" direct exporters will not be able to keep doing so, and will need to resort to intermediaries. Analogously, also some indirect exporters will stop reaching foreign destinations through intermediaries. With relatively mild assumption on the shape of the productivity distribution - whose density we take as monotonically (weakly) decreasing- it turns out that the churning that is expected to take place in the intermediary channel is larger than that involving direct exports. Also this insight from our theory is backed by empirical evidence.

In concluding, our model offers many insights (i) to interpret the different behavior of export intermediaries and direct manufacturing exporters and (ii) to understand how such differences contributes to shape the aggregate patterns of trade flows. Notwithstanding, a few relevant questions remain open for further research. For instance, which are the mechanisms that govern the matching between indirect exporters and intermediaries? This of course goes beyond the simplifying assumptions of random matching and symmetric intermediary firms and would require an appropriate set of data. And, at a more aggregate level, which are the welfare effects of the existence and size of 
the sector of intermediation in international trade? To what extent is it relevant to promote the exports of a country? While, at first, our evidence in this respect is of a positive impact, it is also true that (for obvious reasons) an intermediary is less committed to exporting a given variety, vis $\grave{a}$ vis the direct exporter that also produces the good to be exported. This again raises many issues on the sort of relationship that is established between indirect exporters and trade intermediaries.

\section{References}

Ahn, J., Khandelwal, A. K. and Wei, S.-J. (2011). The role of Intermediaries in Facilitating Trade, Journal of International Economics 84(1): 73-85.

Akerman, A. (forthcoming). A Theory on the Role of Wholesalers in International Trade Based on Economies of Scope, Canadian Journal of Economics .

Amiti, M., Itskhoki, O. and Konings, J. (2014). Importers, Exporters, and Exchange Rate Disconnect, American Economic Review 104(7): 1942-78.

Antràs, P. and Costinot, A. (2011). Intermediated Trade, The Quarterly Journal of Economics 126(3): 1319-1374.

Bai, X., Krishna, K. and Ma, H. (2016). How You Export Matters: Export mode, Learning and Productivity in China, Journal of International Economics 104: 122-137.

Berman, N., Martin, P. and Mayer, T. (2012). How do Different Exporters React to Exchange Rate Changes?, The Quarterly Journal of Economics 127(1): 437-492.

Bernard, A. B., Blanchard, E. J., Beveren, I. V. and Vandenbussche, H. Y. (2012). Carry-Along Trade, NBER Working Papers 18246, National Bureau of Economic Research, Inc.

Bernard, A. B., Grazzi, M. and Tomasi, C. (2011). Intermediaries in international trade: Direct versus indirect modes of export, Technical Report 17711, National Bureau of Economic Research, Inc.

Bernard, A. B., Grazzi, M. and Tomasi, C. (2015). Intermediaries in International Trade: Products and Destinations, The Review of Economics and Statistics 97(4): 916-920.

Bernard, A. B., Jensen, J. B., Redding, S. J. and Schott, P. K. (2010). Wholesalers and Retailers in U.S. Trade, American Economic Review 100(2): 408-13.

Bernini, M. and Tomasi, C. (2015). Exchange Rate Pass-through and Product Heterogeneity: Does Quality Matter on the Import Side?, European Economic Review 77(C): 117-138.

Chaney, T. (2008). Distorted Gravity: the Intensive and Extensive Margins of International Trade, American Economic Review 98(4): 1707-1721. 
Chatterjee, A., Dix-Carneiro, R. and Vichyanond, J. (2013). Multi-product Firms and Exchange Rate Fluctuations, American Economic Journal: Economic Policy 5(2): 77-110.

Corsetti, G. and Dedola, L. (2005). A Macroeconomic Model of International Price Discrimination, Journal of International Economics 67(1): 129-155.

Crozet, M., Lalanne, G. and Poncet, S. (2013). Wholesalers in International Trade, European Economic Review 58(C): 1-17.

Davies, R. and Jeppesen, T. (2015). Export Mode, Firm Heterogeneity, and Source Country Characteristics, Review of World Economics (Weltwirtschaftliches Archiv) 151(2): 169-195.

DiNino, V. (2015). The Phenomenal CAT: Firms Clawing the Goods of Others, Technical Report 281, Bank of Italy, Economic Research and International Relations Area.

Eaton, J., Kortum, S. and Kramarz, F. (2011). An Anatomy of International Trade: Evidence From French Firms, Econometrica 79(5): 1453-1498.

Felbermayr, G. and Jung, B. (2011). Trade Intermediation and the Organization of Exporters, Review of International Economics 19(4): 634-648.

Grazzi, M., Sanzo, R., Secchi, A. and Zeli, A. (2013). The Building Process of a new Integrated System of Business Micro-data 1989-2004, Journal of Economic and Social Measurement 38(4): 291324.

Grazzi, M. and Tomasi, C. (2016). Indirect Exporters and Importers, Review of World Economics (Weltwirtschaftliches Archiv) 152(2): 251-281.

Head, K., Mayer, T. and Thoenig, M. (2014). Welfare and Trade without Pareto, American Economic Review 104(5): 310-16.

Levinsohn, J. and Petrin, A. (2003). Estimating Production Functions Using Inputs to Control for Unobservables, Review of Economic Studies 70(2): 317-41.

Melitz, M. J. (2003). The Impact of Trade on Intra-Industry Reallocations and Aggregate Industry Productivity, Econometrica 71(6): 1695-1725.

Melitz, M. J. and Ottaviano, G. I. P. (2008). Market size, trade, and productivity, Review of Economic Studies 75(1): 295-316.

Mrázová, M., Neary, J. P. and Parenti, M. (2015). Sales and Markup Dispersion: Theory and Empirics, University of oxford, department of economics economics series working papers, 774.

Raff, H. and Schmitt, N. (2006). Exclusive dealing and common agency in international markets, Journal of International Economics 68(2): 485-503.

Raff, H. and Schmitt, N. (2009). Buyer power in international markets, Journal of International Economics 79(2): 222-229. 
Rauch, J. E. and Watson, J. (2004). Network intermediaries in international trade, Journal of Economics \& Management Strategy 13(1): 69-93.

Spengler, J. J. (1950). Vertical Integration and Antitrust Policy, Journal of Political Economy 58: 347-347. 


\section{Appendix A: Mathematical Appendix}

\section{A1 - Productivity cut-offs in the absence of intermediaries}

In this Appendix we show that, in the lack of an export intermediation sector, the critical cut-off level of productivity for entry in the domestic market is

$$
\varphi_{D}=\frac{1}{\left(\frac{\psi A}{f_{D}}\right)^{\frac{1}{\sigma-1}}}, \text { where } \psi \equiv \frac{(\sigma-1)^{\sigma-1}}{\sigma^{\sigma} \delta} .
$$

Proof. This cut-off corresponds to that particular value of $\varphi_{i}$, such that

$$
\pi_{i}=\frac{1}{\delta}\left(p_{i} q_{i}\left(p_{i}\right)-\frac{1}{\varphi_{i}} w_{i} q_{i}\left(p_{i}\right)\right)-f_{D}=0 .
$$

Given $w_{i}=1$, it follows that $\left(\frac{\sigma}{\sigma-1} \frac{1}{\varphi_{i}}-\frac{1}{\varphi_{i}}\right) A\left(p_{i}\right)^{-\sigma}=\delta f_{D}$. With some manipulation, we get

$$
A \varphi_{i}^{\sigma-1}=\underbrace{\delta(\sigma-1)^{1-\sigma} \sigma^{\sigma}}_{\equiv 1 / \psi} f_{D}
$$

which leads to the expression for $\varphi_{D}$ reported in Section 2.2 ,

The critical cut-off level of productivity for entry in the foreign market is instead

$$
\varphi_{X}^{\prime}=\frac{\tau \varepsilon}{\left(\frac{\psi A^{*}}{\varepsilon f_{X}}\right)^{\frac{1}{\sigma-1}}-w^{*} \eta^{*}} .
$$

Proof. This cut-off corresponds to that particular value of $\varphi_{i}$, such that

$$
\pi_{i}^{*}=\frac{1}{\delta}\left(p_{i}^{*} \cdot q_{i}^{*}\left(\widetilde{p}_{i}^{*}\right) \cdot \tau-\frac{1}{\varphi_{i}} \cdot q_{i}^{*}\left(\widetilde{p}_{i}^{*}\right) \cdot \tau\right)-f_{X}=0
$$

Standard steps leads to $\left(\mu_{i}^{*}-1\right) \frac{1}{\varphi_{i}} \cdot A^{*}\left(\widetilde{p}_{i}^{*}\right)^{-\sigma} \cdot \tau=\delta f_{X}$, which can be re-written as

$$
[\underbrace{\frac{\sigma}{\sigma-1}\left(1+\frac{\eta^{*} \varphi_{i}}{\sigma \tau \epsilon}\right)}_{\mu_{i}^{*}}-1] \frac{1}{\varphi_{i}} \cdot A^{*}[\tau \underbrace{\frac{\sigma}{\sigma-1}\left(1+\frac{\eta^{*} \varphi_{i}}{\sigma \tau \epsilon}\right) \frac{1}{\varphi_{i}}}_{p_{i}^{*}}+w^{*} \eta^{*}]^{-\sigma} \cdot \tau=\delta f_{X} .
$$

From the above equation, we get $w^{*} \eta^{*}+\frac{\tau \varepsilon}{\varphi_{i}}=\left[\frac{\psi A^{*}}{\varepsilon f_{X}}\right]^{\frac{1}{\sigma-1}}$ and this, after some simple manipulation, delivers the expression for $\varphi_{X}^{\prime}$ reported above as well as in Section 2.2 .

Finally, we prove that $\varphi_{X}^{\prime}>\varphi_{D}$. This inequality holds if

$$
\tau\left(\frac{\varepsilon^{\sigma} \psi f_{X}}{\psi f_{D}}\right)^{\frac{1}{\sigma-1}}>\left(\frac{A^{*}}{A}\right)^{\frac{1}{\sigma-1}}\left(1-w^{*} \eta^{*}\left(\frac{\varepsilon f_{X}}{\psi A^{*}}\right)^{\frac{1}{\sigma-1}}\right) .
$$


As in Akerman (forthcoming), accounting also for free entry, which implies $E(\pi)=f_{E}$, yields that $A=A^{*}$. The above inequality then turns into

$$
\tau\left(\frac{\varepsilon^{\sigma} f_{X}}{f_{D}}\right)^{\frac{1}{\sigma-1}}>1-w^{*} \eta^{*}\left(\frac{\varepsilon f_{X}}{\psi A^{*}}\right)^{\frac{1}{\sigma-1}}
$$

We can finally conclude that all the previous inequalities hold, conditional on

$$
f_{X}>f_{D}\left[\tau \varepsilon^{\frac{\sigma}{\sigma-1}}+w^{*} \eta^{*}\left(\frac{\psi A^{*}}{\varepsilon f_{D}}\right)^{-\frac{1}{\sigma-1}}\right]^{1-\sigma} .
$$

\section{A2 - Comparison among markups}

This appendix provides a formal proof of Results 1 and 2 reported in Section 3.1 .

Proof. We split the proof of Result 1 in two halves. In this first one, we prove that $\mu_{i j}$ (i.e. the indirect exporter's markup, in case good $i$ is traded through a generic intermediary $j$ ) is larger than $\mu_{i}$ (i.e. the Dixit-Stilglitz markup applied by firm $i$ when selling its variety to national consumers). Given the expressions of the two markups, respectively from equations (5) and (1), in order for $\mu_{i j}$ to be larger than $\mu_{i}$ we must verify that

$$
\underbrace{\frac{(\sigma-1)^{2}}{\sigma(\sigma-2)}}_{>1}(1+\underbrace{\frac{\eta * \varphi_{i}}{(\sigma-1) \epsilon \tau}}_{>0})>1 .
$$

This inequality holds for any admissible value of $\sigma$, since $(\sigma-1)^{2} /[\sigma(\sigma-2)]>1$ is always true for $\sigma>2$; and $\eta^{*} \varphi_{i} /[(\sigma-1) \epsilon \tau]>0$ is verified for any $\sigma>1$ (our assumption is $\sigma>2$ ).

Proof. The second part of the proof entails a comparison between $\mu_{i j}$, i. e. the indirect exporter's markup that applies when variety $i$ is traded indirectly, and $\mu_{i}^{*}$, which is the markup that firm $i$ would apply in case of direct export, reported in equation (2). If $\mu_{i j}>\mu_{i}^{*}$, then

$$
\frac{\sigma-1}{\sigma-2}\left(1+\frac{\eta^{*} \varphi_{i}}{(\sigma-1) \epsilon \tau}\right)>\frac{\sigma}{\sigma-1}\left(1+\frac{\eta^{*} \varphi_{i}}{\sigma \tau \epsilon}\right)
$$

which is true provided that $\eta^{*} \varphi_{i} /(\tau \epsilon)>-1$. However, this condition is always satisfied, since $\varphi_{i}, \eta^{*}, \epsilon$ and $\tau$ are all positive real numbers.

Proof. Finally, we prove that $\mu_{i j}$, i.e. the indirect exporter's markup when variety $i$ is traded through intermediary $j$ is larger then $\mu_{j}^{*}$, i.e. the intermediary $j$ 's markup charged on this product, according to equation (4). This corresponds to Result 2. The condition of our interest is

$$
\frac{\sigma-1}{\sigma-2}\left(1+\frac{\eta^{*} \varphi_{i}}{(\sigma-1) \epsilon \tau}\right)>\frac{\sigma \epsilon \tau+2 \eta^{*} \varphi_{i}}{(\sigma-1) \epsilon \tau+\eta^{*} \varphi_{i}}
$$


and it is straightforward to show that this inequality is always verified, since the polynomial $\left(\eta^{*} \varphi_{i}\right)^{2}+2 \epsilon \tau \eta^{*} \varphi_{i}+(\epsilon \tau)^{2}$ is larger than zero, given $\varphi_{i}, \eta^{*}, \epsilon$ and $\tau \in(0,+\infty)$.

\section{A3 - Export mode selection}

In this Appendix we show how productivity sorting characterizes the selection of the mode of export of each firm. For producer $i$, the expected profit from direct export sales (discounted by the forced exit rate) is

$$
\pi_{i}^{*}=\frac{1}{\delta}\left[p_{i}^{*} \cdot q_{i}^{*}\left(\widetilde{p}_{i}^{*}\right) \cdot \tau-\frac{1}{\varphi_{i}} \cdot q_{i}^{*}\left(\widetilde{p}_{i}^{*}\right) \cdot \tau\right]-f_{X^{d i r}}=\frac{(\sigma-1)^{\sigma-1}}{\sigma^{\sigma} \delta} \frac{A^{*}}{\varepsilon} \cdot\left(\frac{\tau \varepsilon}{\varphi_{i}}+w^{*} \eta^{*}\right)^{1-\sigma}-f_{X},
$$

whereas the expected (discounted) profit from indirect export sales through intermediary $j$ is

$$
\pi_{i j}=\frac{1}{\delta}\left[p_{i j} \cdot q_{i j}^{*}\left(\widetilde{p}_{i j}^{*}\right) \cdot \tau-\frac{1}{\varphi_{i}} \cdot q_{i j}^{*}\left(\widetilde{p}_{i j}^{*}\right) \cdot \tau\right]-f_{X^{i n d}}=\frac{(\sigma-2)^{\sigma-1}}{\sigma^{\sigma} \delta} \frac{A^{*}}{\varepsilon} \cdot\left(\frac{\tau \varepsilon}{\varphi_{i}}+w^{*} \eta^{*}\right)^{1-\sigma}-\lambda f_{X} .
$$

The minimum level of productivity for a direct entry in the foreign market can be proved to be

$$
\varphi_{X} \text { dir } \equiv \frac{\tau \varepsilon}{\left(\frac{\phi A^{*}}{\varepsilon f_{X}}\right)^{\frac{1}{\sigma-1}}-w^{*} \eta^{*}}, \text { where } \phi \equiv \frac{(\sigma-1)^{\sigma-1}-(\sigma-2)^{\sigma-1}}{\sigma^{\sigma} \delta} .
$$

Proof. The choice of exporting directly, rather than indirectly, is motivated by the occurrence of the following condition: $\pi_{i}^{*}>\pi_{i j}$. This implies

$$
\frac{(\sigma-1)^{\sigma-1}}{\sigma^{\sigma} \delta} \frac{A^{*}}{\varepsilon} \cdot\left(\frac{\tau \varepsilon}{\varphi_{i}}+w^{*} \eta^{*}\right)^{1-\sigma}-f_{X}>\frac{(\sigma-2)^{\sigma-1}}{\delta \sigma^{\sigma}} \frac{A^{*}}{\varepsilon} \cdot\left(\frac{\tau \varepsilon}{\varphi_{i}}+w^{*} \eta^{*}\right)^{1-\sigma}-\lambda f_{X} .
$$

The inequality reduces as follows

$$
\varphi_{i}>\frac{\tau \varepsilon}{\left(\frac{\phi A^{*}}{\varepsilon(1-\lambda) f_{X}}\right)^{\frac{1}{\sigma-1}}-w^{*} \eta^{*}},
$$

where $\phi$ is a constant term that depends only on $\sigma$ and $\delta$. The above condition identifies the cut-off level of our interest, which is the one reported in equation (11) in Section $3.3^{26}$

Given the profits associated with the two export modes, the critical cut-off for indirect entry in the overseas market is

$$
\varphi_{X^{i n d}}=\frac{\tau \varepsilon}{\left(\frac{\chi A^{*}}{\varepsilon \lambda f_{X}}\right)^{\frac{1}{\sigma-1}}-w^{*} \eta^{*}}, \text { where } \chi \equiv \frac{(\sigma-2)^{\sigma-1}}{\sigma^{\sigma} \delta}
$$

and $\lambda f_{X}=f_{X^{i n d}}$ is the fixed cost that each producer has to pay in order to gain access to the services of a trade intermediary, this cost being a fraction $\lambda$ of the fixed cost of (direct) entry in the destination market, namely $f_{X^{d i r}}=f_{X}$.

\footnotetext{
${ }^{26}$ To draw a parallel with the simpler model of Akerman (forthcoming) with no local distribution costs, in its setting the direct-export cut-off turns out to be: $\left(\varphi_{X \text { dir }}\right)^{A k e}=\left[f_{X} /\left(\tau^{1-\sigma} \psi A^{*}\left(1-\left(\frac{\sigma-1}{\sigma}\right)^{\sigma}\right)\right)\right]^{\frac{1}{\sigma-1}}=\tau /\left[\bar{\phi} A^{*} / f_{X}\right]^{-\frac{1}{\sigma-1}}$, where $\bar{\phi} \equiv(1 / \psi) \cdot\left[1-\left(\frac{\sigma-1}{\sigma}\right)^{\sigma}\right]^{-1}=\frac{\sigma^{\sigma}-(\sigma-1)^{\sigma}}{(\sigma-1)^{1-\sigma} \sigma^{2 \sigma \delta}}$.
} 
Proof. The choice of exporting indirectly, rather than serving only the domestic market, is motivated by the occurrence of the condition $\pi_{i j}>0$, which entails

$$
\frac{(\sigma-2)^{\sigma-1}}{\delta \sigma^{\sigma}} \frac{A^{*}}{\varepsilon} \cdot\left(\frac{\tau \varepsilon}{\varphi_{i}}+w^{*} \eta^{*}\right)^{1-\sigma}>f_{X^{i n d}}=\lambda f_{X} .
$$

With some simple algebra, this condition reduces to the following restriction

$$
\varphi_{i}>\frac{\tau \varepsilon}{\left(\frac{\chi A^{*}}{\varepsilon \lambda f_{X}}\right)^{\frac{1}{\sigma-1}}-w^{*} \eta^{*}}, \text { where } \chi \equiv \frac{(\sigma-2)^{\sigma-1}}{\sigma^{\sigma} \delta} .
$$

This identifies the indirect export cut-off, as reported in equation $(12)$ in Section $3.3^{27}$

If $\lambda$ is small enough, than the model generates a standard result of productivity sorting as regards the choice of the export mode. The most productive firms, i.e. those with productivity $\varphi_{i}>\varphi_{X^{d i r}}$, will export directly, as they are productive enough to take the fixed cost of exporting themselves, thereby avoiding double marginalization for their products. Firms with intermediate levels of productivity, i.e. those with $\varphi_{i} \in\left(\varphi_{X^{i n d}}, \varphi_{X^{\text {dir }}}\right)$, will export through the intermediary sector. Finally, the least productive firms, i.e. those with productivity $\varphi_{i} \in\left(\varphi_{D}, \varphi_{X^{i n d}}\right)$, will do not engage in export activity and will serve the domestic market only. This last result, in particular, holds conditional on imposing the following restriction

$$
\lambda f_{X}>\frac{\chi}{\psi} f_{D}\left[\tau \varepsilon^{\frac{\sigma}{\sigma-1}}+w^{*} \eta^{*}\left(\frac{\psi A^{*}}{\varepsilon f_{D}}\right)^{-\frac{1}{\sigma-1}}\right]^{1-\sigma},
$$

where $f_{D}$ is the fixed cost of entry in the domestic market, sunk by all firms with productivity larger than $\varphi_{D}$.

Proof. It is straightforward to prove that $\varphi_{X \text { dir }}>\varphi_{X^{i n d}}$ as long as we restrict $\lambda$ to be lower than a given threshold, to be determined hereinafter. Given the expressions of the two cut-off levels, $\varphi_{X}$ dir $>\varphi_{X}$ ind necessarily implies

$$
\frac{\chi A^{*}}{\varepsilon \lambda f_{X}}>\frac{\phi A^{*}}{\varepsilon(1-\lambda) f_{X}}
$$

which is always verified as far as $\lambda<\left(\frac{\sigma-2}{\sigma-1}\right)^{\sigma-1}$.

Under the above restriction, only the most productive among the firms able to export in the absence of an intermediary sector will actually prefer to export directly, rather than indirectly, once the intermediary sector has been introduced. The other firms will keep exporting, but they will find more convenient to do so by using intermediaries, rather than by managing directly the exchange.

Furthermore, if $\varphi_{X^{\text {ind }}}>\varphi_{D}$ holds, then we have

$$
\frac{\tau \varepsilon}{\left(\frac{\chi A^{*}}{\varepsilon \lambda f_{X}}\right)^{\frac{1}{\sigma-1}}-w^{*} \eta^{*}}>\frac{1}{\left(\frac{\psi A^{*}}{f_{X}}\right)^{\frac{1}{\sigma-1}}} .
$$

\footnotetext{
${ }^{27} \operatorname{In}$ Akerman (forthcoming) the corresponding cutoff is determined by accounting for the optimal scope of wholesalers when solving for the equilibrium, as long as manufacturing firms may access to the services provided by a trade intermediary without incurring a fixed $\operatorname{cost}(\lambda=0)$, but intermediaries incurs in a cost when adding new varieties to their export basket.
} 
As in Appendix A, free entry implies that $A=A^{*}$. The inequality then turns into

$$
f_{X}>\frac{\chi}{\lambda \psi} f_{D}\left[\tau \varepsilon^{\frac{\sigma}{\sigma-1}}+w^{*} \eta^{*}\left(\frac{\psi A^{*}}{\varepsilon f_{D}}\right)^{-\frac{1}{\sigma-1}}\right]^{1-\sigma}
$$

which is the counterpart, for the model with intermediaries, of the condition (3), namely

$$
f_{X}>f_{D}\left[\tau \varepsilon^{\frac{\sigma}{\sigma-1}}+w^{*} \eta^{*}\left(\frac{\psi A^{*}}{\varepsilon f_{D}}\right)^{-\frac{1}{\sigma-1}}\right]^{1-\sigma},
$$

that must be imposed in the model without intermediaries to ensure that manufacturing firms cannot be exporters without being able to serve first their own domestic market.

Provided that $\lambda$ is small enough, our model then predicts that the export cut-off in the absence of intermediaries, namely $\varphi_{X}^{\prime}$, is (i) lower than the direct-export cutoff in the presence of an intermediary sector, i.e. $\varphi_{X}$ dir ; and (ii) larger than the indirect-export cutoff, namely $\varphi_{X^{\text {ind }}}$. This means that, when introducing trade intermediaries, the basket of goods traded along the indirect export channel will include both:

- goods produced by manufacturers that would be able to export by their own (even in the absence of an intermediation sector), but find more profitable to use intermediaries, when the latter are available;

- goods produced by firms that, because of their lower marginal productivity, would not be able export if not assisted, and therefore manage to reach the overseas markets only thanks to the presence of intermediaries.

Proof. It is straightforward to prove that $\varphi_{X^{d i r}}>\varphi_{X}^{\prime}$ conditional on $\lambda$ being sufficiently small. In fact, $\varphi_{X}$ dir $>\varphi_{X}^{\prime}$ necessarily implies

$$
\frac{\tau \varepsilon}{\left(\frac{\phi A^{*}}{\varepsilon(1-\lambda) f_{X}}\right)^{\frac{1}{\sigma-1}}-w^{*} \eta^{*}}>\frac{\tau \varepsilon}{\left(\frac{\psi A^{*}}{\varepsilon f_{X}}\right)^{\frac{1}{\sigma-1}}-w^{*} \eta^{*}}
$$

which is always verified as far as $(1-\lambda) \psi>\phi$, a condition that can be reduced to $\lambda<\left(\frac{\sigma-2}{\sigma-1}\right)^{\sigma-1}$.

Under this restriction, we can also prove that

$$
\frac{\tau \varepsilon}{\left(\frac{\chi A^{*}}{\varepsilon \lambda f_{X}}\right)^{\frac{1}{\sigma-1}}-w^{*} \eta^{*}}<\frac{\tau \varepsilon}{\left(\frac{A^{*}}{\varepsilon \psi f_{X}}\right)^{\frac{1}{\sigma-1}}-w^{*} \eta^{*}},
$$

which means $\varphi_{X^{i n d}}<\varphi_{X}^{\prime}$. Indeed, the above condition is satisfied for $\psi \lambda<\chi$, which is always true, again, if $\lambda<[(\sigma-2) /(\sigma-1)]^{\sigma-1}$.

Notice that, under the above restriction on $\lambda$ (which leads to productivity sorting as in the manner of most of the related literature) the condition that must be imposed to prevent firms from selecting in the export market without selecting also in the domestic market is more severe in the model with intermediaries, than in the model without. 
In the setting with the intermediation sector, $\varphi_{X \text { dir }}>\varphi_{D}$ necessarily implies

$$
f_{X}>\frac{\chi}{\psi \lambda} f_{D}\left[\tau \varepsilon^{\frac{\sigma}{\sigma-1}}+w^{*} \eta^{*}\left(\frac{\psi A^{*}}{\varepsilon f_{D}}\right)^{-\frac{1}{\sigma-1}}\right]^{1-\sigma} \equiv F_{X}
$$

while, in the model without intermediaries, the fact that $\varphi_{X}^{\prime}>\varphi_{D}$ implies

$$
f_{X}>f_{D}\left[\tau \varepsilon^{\frac{\sigma}{\sigma-1}}+w^{*} \eta^{*}\left(\frac{\psi A^{*}}{\varepsilon f_{D}}\right)^{-\frac{1}{\sigma-1}}\right]^{1-\sigma} \equiv F_{X}^{\prime} .
$$

It can be proved that $F_{X}>F_{X}^{\prime}$ as long as $\lambda<\chi / \psi$ or, equivalently, $\lambda<[(\sigma-2) /(\sigma-1)]^{\sigma-1}$, in line with the restriction imposed to ensure that $\varphi_{X^{i n d}}<\varphi_{X}^{\prime}<\varphi_{X^{d i r}}$.

\section{A4 - Comparison of the export cut-off elasticities}

This appendix provides a proof for condition $(13)$, which states that, if $\lambda<[(\sigma-2) /(\sigma-1)]^{\sigma-1}$, then the indirect-export productivity cut-off is more elastic to the RER than the direct-export cut-off.

Proof. The inequality reported in $(13)$ can be expressed as

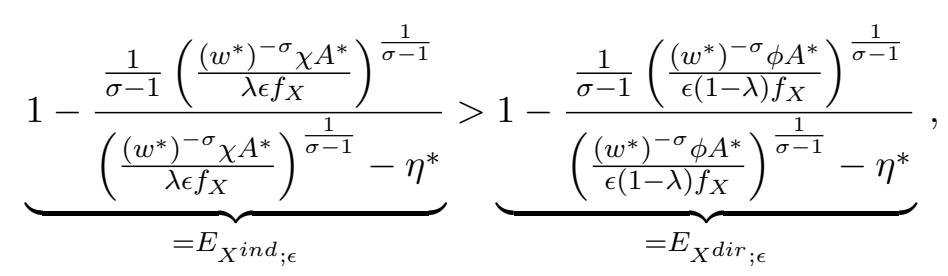

where both the cut-off elasticities are written as a function of the RER, i.e. $\epsilon=\varepsilon w^{*} / w$ (with $w=1$ ), instead of the nominal exchange rate $\varepsilon$. The above condition can be reduced to

$$
\eta^{*}\left[1-\left(\frac{\phi \lambda}{\chi(1-\lambda)}\right)^{\frac{1}{\sigma-1}}\right]>0
$$

and then to $\left(\frac{\phi \lambda}{\chi(1-\lambda)}\right)^{\frac{1}{\sigma-1}}<1$, given $\eta^{*}>0$.

Since $1 /(\sigma-1)>0$ is certainly a positive number (given $\sigma>2$ ), we can conclude that inequality (13) holds as far as

$$
\underbrace{\frac{(\sigma-1)^{\sigma-1}-(\sigma-2)^{\sigma-1}}{\sigma^{\sigma} \delta}}_{\equiv \phi} \cdot \lambda<\underbrace{\frac{(\sigma-2)^{\sigma-1}}{\sigma^{\sigma} \delta}}_{\equiv \chi} \cdot(1-\lambda),
$$

which leads us again to the usual fundamental condition, that is $\lambda<\left(\frac{\sigma-2}{\sigma-1}\right)^{\sigma-1}$. 


\section{Appendix B: Empirical Appendix}

Table B1: Exchange rates and firm's export values, quantities and unit values by product and country over time, by different type of firms, Extra-EU: using Wholesaler Price Index

\begin{tabular}{lccc}
\hline & \multicolumn{3}{c}{ Annual Differences } \\
\hline & $\ln \mathrm{X}_{f c p t}$ & $\begin{array}{l}\text { ln UnitValue } \\
\text { fcpt }\end{array}$ & $\ln$ Quantity $_{f c p t}$ \\
& $(1)$ & $(2)$ & $(3)$ \\
\hline ln RER $_{c t}$ & $-0.352^{* * *}$ & $-0.039^{* * *}$ & $-0.313^{* *}$ \\
\multirow{2}{*}{$* D_{f t}^{W}$} & $(0.135)$ & $(0.012)$ & $(0.138)$ \\
& $0.037^{* *}$ & $-0.035^{* *}$ & $0.072^{* *}$ \\
& $(0.15)$ & $(0.017)$ & $(0.35)$ \\
Country FE & & & \\
Year FE & Yes & Yes & Yes \\
Firm-Product FE & Yes & Yes & Yes \\
Clustering Country-Year & Yes & Yes & Yes \\
& & Yes & Yes \\
Adj R-squared & -0.011 & 0.033 & -0.012 \\
Observations & 3655626 & 3655626 & 3655626 \\
\hline
\end{tabular}

Note: Table reports the results of regressions at the firm-product-country level, obtained by using data on export values, quantities and unit values between 2000 and 2007. The dependent variables and the real exchange rates (RER) are defined as annual differences. $D_{f t}^{W}$ is a dummy for intermediaries; $* D_{f t}^{W}$ is the interaction term with real exchange rates in annual differences. Robust standard errors clustered at country-year level are reported in parenthesis below the coefficients. Asterisks denote significance levels (***: $\mathrm{p}<1 \%$; $*$ : $\mathrm{p}<5 \%$; $: \mathrm{p}<10 \%$ ). Source: Our elaboration on Italian micro-data.

Table B2: Firms' productivity and Exchange Rate Changes

\begin{tabular}{|c|c|c|c|c|c|c|}
\hline Sample & Single Prod & $\begin{array}{l}\text { Main Prod } \\
\text { (by value) }\end{array}$ & $\begin{array}{l}\text { Main Prod } \\
\text { (by destin.) }\end{array}$ & Single Prod & $\begin{array}{l}\text { Main Prod } \\
\text { (by value) }\end{array}$ & $\begin{array}{l}\text { Main Prod } \\
\text { (by destin.) }\end{array}$ \\
\hline & ln UnitValue $f_{c p t}$ & ln UnitValue ${ }_{f c p t}$ & ln UnitValue ${ }_{f c p t}$ & ln Export $_{f c p t}$ & $\ln$ Export $_{f c p t}$ & $\ln$ Export $_{f c p t}$ \\
\hline$\widetilde{T F P} P_{t-1}$ & $\begin{array}{c}0.027^{* * *} \\
(0.007)\end{array}$ & $\begin{array}{c}0.030 * * * \\
(0.004)\end{array}$ & $\begin{array}{c}0.031^{* * *} \\
(0.005)\end{array}$ & $\begin{array}{c}0.053^{* * *} \\
(0.018)\end{array}$ & $\begin{array}{c}0.072^{* * *} \\
(0.012)\end{array}$ & $\begin{array}{c}0.066^{* * *} \\
(0.011)\end{array}$ \\
\hline ln RER & $\begin{array}{l}-0.015 \\
(0.010)\end{array}$ & $\begin{array}{c}-0.043^{* * *} \\
(0.013)\end{array}$ & $\begin{array}{c}-0.034^{* *} \\
(0.015)\end{array}$ & $\begin{array}{c}-0.408^{* * *} \\
(0.098)\end{array}$ & $\begin{array}{c}-0.522^{* * *} \\
(0.117)\end{array}$ & $\begin{array}{c}-0.454^{* * *} \\
(0.114)\end{array}$ \\
\hline$\widetilde{T F P}{ }_{t-1} * \ln \mathrm{RER}$ & $\begin{array}{c}-0.005^{* *} \\
(0.002)\end{array}$ & $\begin{array}{l}-0.003 \\
(0.002)\end{array}$ & $\begin{array}{l}-0.003^{*} \\
(0.001)\end{array}$ & $\begin{array}{l}0.004^{*} \\
(0.002)\end{array}$ & $\begin{array}{c}0.002 \\
(0.003)\end{array}$ & $\begin{array}{c}0.005^{* *} \\
(0.002)\end{array}$ \\
\hline Year FE & Yes & Yes & Yes & Yes & Yes & Yes \\
\hline Firm-Country FE & Yes & Yes & Yes & Yes & Yes & Yes \\
\hline Cluster Country-Year & Yes & Yes & Yes & Yes & Yes & Yes \\
\hline Adj R-squared & 0.951 & 0.959 & 0.938 & 0.724 & 0.753 & 0.716 \\
\hline Observations & 308748 & 662220 & 776367 & 308748 & 662220 & 776367 \\
\hline
\end{tabular}

Note: Table reports results of regressions at the firm-product-country level, using cross-border Italian data on export values, quantities and unit values of exported products for the period 2000-2006. We merged the ISTAT trade data with Micro.3, which contains firm-level variables to be used for computing firm-level TFP. We keep single product, main product by value and main product by destination observations and we run the regression as in Berman et al. (2012). Source: Our elaboration on Italian micro-data. 
In this Appendix we verify that the result of Berman et al. (2012, BMM hereinafter) holds also for the case of Italian firms. To accomplish this task, we focus on manufacturing firms only and we exploit the same methodology as in BMM to deal with the existence of multi-product firms. Hence, we consider three samples. The first (Single Product) contains single product-anddestination specific observations, i.e. observations referred to firms that export only one product to a given destination. The second (Main Product by value) keeps only the top product (in terms of export value) exported by the firm worldwide. Finally, the last (Main Product by destination) considers again the top product only, but here the latter is defined as the variety exported to the largest number of destinations.

The estimated equation is

$$
\ln Y_{f c t}=\beta_{0}+\beta_{1} \widetilde{T F P}_{f t-1}+\beta_{2} \ln R E R_{c t}+\beta_{3} \widetilde{T F P}_{f t-1} * \ln R E R_{c t}+d_{j}+\nu_{f c t}
$$

where $Y_{f c t}$ is, alternatively, the firm-level unit value or the export value of the single or main product (depending on the sample used), whereas $\widetilde{T F P}_{f t-1}$ denotes the productivity of the firm $f$ in year $t-1$, normalized by the average industry productivity computed in that year. The results are reported in Table B2 and are coherent with the findings of BMM: more productive firms tend to increase more their export prices in response to currency depreciations. As a result, their export sales display a smaller increase when compared to firms with lower TFP. 


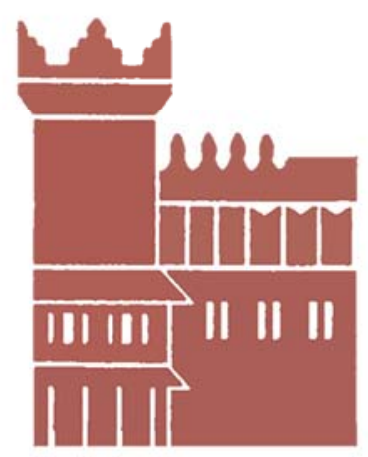

Alma Mater Studiorum - Università di Bologna DEPARTMENT OF ECONOMICS

Strada Maggiore 45

40125 Bologna - Italy

Tel. +39051 2092604

Fax +390512092664

http://www.dse.unibo.it 